\title{
Immune Inhibitor A Metalloproteases Contribute to Virulence in Bacillus Endophthalmitis
}

Erin T. Livingston ${ }^{1}$, Md Huzzatul Mursalin ${ }^{1}$, Phillip S. Coburn ${ }^{2}$, Roger Astley ${ }^{2}$, Frederick C. Miller $^{3,4}$, Omar Amayem ${ }^{2}$, Didier Lereclus ${ }^{6}$, Michelle C. Callegan ${ }^{1,2,5,7 *}$

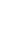

8

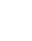

${ }^{1}$ Department of Microbiology and Immunology, The University of Oklahoma Health Sciences Center, Oklahoma City, Oklahoma, United States of America

${ }^{2}$ Department of Ophthalmology, The University of Oklahoma Health Sciences Center, Oklahoma City, Oklahoma, United States of America

${ }^{3}$ Department of Cell Biology, The University of Oklahoma Health Sciences Center, Oklahoma City, Oklahoma, United States of America

${ }^{4}$ Department of Family and Preventive Medicine, The University of Oklahoma Health Sciences Center, Oklahoma City, Oklahoma, United States of America

${ }^{5}$ Dean McGee Eye Institute, Oklahoma City, Oklahoma, United States of America

${ }^{6}$ Micalis Institute, INRAE, AgroParisTech, Université Paris-Saclay, 78350 Jouy-en-Josas, France

${ }^{7}$ Oklahoma Center for Neuroscience, The University of Oklahoma Health Sciences Center, Oklahoma City, Oklahoma, United States of America

${ }^{a}$ Current Address: Department of Microbiology and Immunology, The University of Oklahoma Health Sciences Center, 940 Stanton L. Young Blvd., BMSB 1053 Oklahoma City, Oklahoma, 73104, United States of America

$26 *$ Corresponding author

27 E-mail: michelle-callegan@ouhsc.edu (MC) 


\section{Abstract}

Bacterial endophthalmitis is a devastating infection that can cause blindness following the introduction of organisms into the posterior segment of the eye. Over half of Bacillus endophthalmitis cases result in significant loss of useful vision. Often, these eyes have to be enucleated. Bacillus produces many virulence factors in the eye that may contribute to retinal damage and robust inflammation. This study analyzed Bacillus immune inhibitor A (InhA) metalloproteases, which digest extracellular matrix, tight junction proteins, and antimicrobial proteins. We hypothesized that InhAs contribute to Bacillus intraocular virulence and inflammation. We analyzed phenotypes and infectivity of wild type (WT), InhA1-deficient

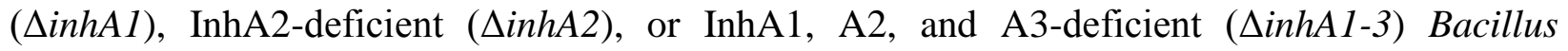
thuringiensis. In vitro analysis of growth, proteolysis, and cytotoxicity were compared between $B$. thuringiensis strains. WT and InhA mutants were similarly cytotoxic to retinal cells. Mutant $\triangle i n h A 1$ and $\triangle i n h A 2$ entered $\log$ phase growth earlier than WT. Proteolysis of the $\triangle i n h A 1-3$ mutant was decreased, but this strain grew similar to WT in vitro. Experimental endophthalmitis was initiated by intravitreally infecting C57BL/6J mice with $200 \mathrm{CFU}$ of B. thuringiensis WT or InhA mutants. Intraocular Bacillus and retinal function loss were quantified. Intraocular myeloperoxidase concentrations were quantified and histology was analyzed. Eyes infected with $\triangle i n h A 1$ or $\triangle i n h A 2$ strains contained greater numbers of bacteria than eyes infected with WT throughout the course of infection. Eyes infected with single mutants had inflammation and retinal function loss similar to eyes infected with WT strain. Eyes infected with $\Delta i n h A 1-3$ cleared the infection, with less retinal function loss and inflammation compared to eyes infected with the WT strain. RT-PCR results suggested that single InhA mutant results may be explained by compensatory expression of the other InhAs in these mutants. These results indicate that together, the InhA metalloproteases contribute to the severity of infection and inflammation in Bacillus endophthalmitis.

\section{Author summary}

Bacterial endophthalmitis is an infection of the eye, which can follow accidental contamination of the posterior segment following ocular surgery (postoperative), a penetrating wound (post- 
59 bacterial endophthalmitis, virulent pathogens such as Bacillus cause ocular damage via the 60 activities of an array of virulence factors, including proteases. A class of proteases that are 61 expressed by Bacillus during ocular infection are the immune inhibitor A metalloproteases. Here, 62 we used a mouse model of endophthalmitis to test mutant Bacillus that lack single or multiple 63 InhAs to determine if these metalloproteases contributed to the virulence during the disease. In the 64 absence of the production of all InhAs, Bacillus could not cause severe infection. Our study 65 provides new insights into the virulence of Bacillus in the eye, and the contribution of its InhA 66 metalloproteases to establishing infection.

67 


\section{Introduction}

One of the most severe forms of intraocular inflammation and rapid vision loss caused by bacteria is due to infection with Bacillus spp. [1-6]. Bacillus endophthalmitis occurs most often following ocular trauma involving a foreign body contaminated with this bacterium [7-11]. Despite treatment with antibiotics, anti-inflammatory drugs, and surgical intervention, more than $70 \%$ of patients with Bacillus endophthalmitis have been documented to have significant vision loss, and about $50 \%$ of those patients underwent evisceration or enucleation of the infected eye [7-11]. Because this feared infection is difficult to treat, there is great importance in identifying virulence factors of Bacillus that contribute to this blinding disease.

Bacillus thuringiensis belongs to the Bacillus cereus sensu lato group, and is known for causing severe bacterial endophthalmitis $[1,12]$. B. thuringiensis is so genetically similar to $B$. cereus that the species delineation between the two within the sensu lato group has been problematic despite the various approaches and techniques used [13]. Studies comparing the genomes of both organisms have suggested that they belong to the same species [14]. It has also been reported that the genetic and phenotypic properties between these bacteria are barely distinguishable [15]. Both organisms replicate quickly in the eye, are highly motile, and express similar virulence factors - all of which may contribute to the severity of endophthalmitis [12,1619].

The majority of extracellular Bacillus virulence factors are produced under the control of a global regulator, PlcR. An absence of a functioning PlcR system delayed the damage typically seen in Bacillus endophthalmitis [16,19-21]. In intraocular infections with mutants lacking a functional PlcR system, there was still retinal toxicity, function loss, and vascular permeability. Virulence factors outside of $p l c R$ regulation that may have contributed to this delayed response might include cell wall endopeptidases, S-layer, hemolysins, InhA1 metalloprotease, amidases, pili, and/or flagella components [20-27]. Our previous work showed that individual toxins, such as hemolysin BL, phosphatidycholine-specific phospholipase C (PC-PLC), or

94 phosphatidylinositol-specific phospholipase C (PI-PLC), contributed little to the disease $[17,18]$.

95 Recently, we observed that specific virulence factors are highly expressed in explanted vitreous 96 and in mouse eyes, including the immune inhibitor metalloproteases InhA1 and InhA2 [28,29]. A

97 greater expression of InhA2 was detected in explanted vitreous compared to the levels detected in 
LB and BHI media. For InhA1, the expression in explanted vitreous was similar to InhA1 expression in BHI. A pangenome-wide study of ocular Bacillus isolates also reported molecular signatures of specific virulence factors, including the InhAs, which were strongly associated with this intraocular infection [30].

The InhA proteins are metalloproteases containing zinc-binding and catalytic active site residues similar to other metalloproteases such as PrtV of Vibrio cholera, thermolysin from Bacillus thermopoteolyticus, E-15 from Serratia, and elastase from Pseudomonas aeruginosa [31,32]. InhA1 is secreted by Bacillus during all phases of growth, and is associated with the exosporium [33]. The regulation of InhA1 is dependent on Spo0A, the key factor involved in the initiation of sporulation, and AbrB, which regulates sporulation gene expression [34,35]. InhA1 has been reported to hydrolyze the insect antibacterial proteins cecropin and attacin [36], degrade extracellular matrix proteins, and cleave fibronectin, laminin, and collagens types I and IV in tissue [37,38]. InhA1 also cleaves various exported proteins, including the protease NprA (Npr599 in Bacillus anthracis) [39]. Additionally, InhA1 contributes to B. cereus spore escape from macrophages [40,41]. Injection of purified $B$. anthracis InhA1 and nanoparticles conjugated to $B$. anthracis InhA1 into mice resulted in blood-brain barrier permeability, suggesting a potential role for InhA1 in meningitis [37].

More is known about InhA1 than about the other InhAs of Bacillus. InhA1 has a $66 \%$ protein identity to InhA 2 and a $72 \%$ protein identity to InhA3. All three metalloproteases are secreted and contain a zinc-binding domain. InhA2 is involved in toxicity of Galleria mellonella after oral inoculation of spores, but InhA2 alone is not sufficient for virulence in this model $[42,43]$. In contrast to InhA1, InhA2 is regulated by PlcR and is repressed by Spo0A $[25,43]$. The transcription of $i n h A 3$ is activated at the onset of sporulation by the quorum sensor NprR [44]. The specific functions of InhA2 and InhA3 in infection have not yet been described.

Due to the InhAs potential role in degrading important host tissue components and disrupting barriers, and the evidence that InhAs are expressed in an ocular infection-related environment, we hypothesized that the InhAs are involved in the Bacillus endophthalmitis pathogenesis. We used a well-characterized experimental model of endophthalmitis in mice to mimic human infection. Our study demonstrated that the absence of all three InhAs (InhA1, InhA2, and InhA3) together significantly reduced Bacillus virulence during ocular infection. Better 
128

129

130

131

132

133

134

135

136

137

138

139

140

141

142

143

144

145

146

147

148

149

150

151

152

153

154

155

156

knowledge of the underlying mechanisms of these virulence factors in the eye could lead to the identification of possible therapeutic targets that prevent vision loss in endophthalmitis patients.

\section{Results}

\section{Absence of InhA1 in Bacillus Alters Growth and Proteolysis}

The phenotypes of $B$. thuringiensis 407 (WT) and its isogenic InhA1-deficient mutant $(\triangle i n h A 1)$ were compared. WT and $\triangle i n h A l$ in vitro growth were compared by subculturing overnight cultures into fresh brain heart infusion (BHI) broth and quantifying every 2 hours. Figure 1 A demonstrates that $\triangle i n h A l$ had higher bacterial concentrations at 2, 4, and 6 hours compared to that of the WT strain, starting as early as 2 hours $(\mathrm{P}=0.0263,0.0065,0.0059$, respectively). Both strains reached similar concentrations at stationary phase at 8 hours. However, the overall growth rates were not different between the two strains $(\mathrm{P}=0.2500$, Figure $1 \mathrm{~B})$, suggesting that $\Delta i n h A 1$ entered exponential phase earlier than WT. In Figure 1C, hemolytic titers of 18 hour WT and $\Delta i n h A 1$ supernatants were similar $(\mathrm{P} \geq 0.8678)$. Figure $1 \mathrm{D}$ shows the comparison of supernatant cytotoxicity of WT and $\triangle i n h A l$ on human retinal pigment epithelial cells (RPEs). The strains had similar cytotoxicity $(\mathrm{P}=0.0700)$. Proteolysis of $\mathrm{WT}$ and $\Delta i n h A l$ on skim milk agar plates was also compared (Figure 1E). Clear lytic zone sizes around colonies were significantly different, with the $\triangle i n h A 1$ B. thuringiensis exhibiting smaller proteolytic zones $(\mathrm{P}=0.0006)$. Together, these results suggested that an absence of InhA1 affected bacterial growth and proteolytic activity, but not hemolysis or cytotoxicity.

\section{Absence of InhA1 Affects Intraocular Bacterial Burden But Not Inflammation in Endophthalmitis}

The intraocular growth of WT and $\triangle i n h A 1 B$. thuringiensis was quantified in the eyes of C57BL/6J mice (Figure 2). Mouse eyes were infected with approximately $200 \mathrm{CFU} / \mathrm{eye}$ of either WT or $\Delta i n h A 1$ B. thuringiensis. At 6, 8, 10, and 12 hours postinfection, eyes were harvested and homogenized. Homogenates were plated on BHI agar and colonies were counted to quantify intraocular concentration (Figure 2A). Myeloperoxidase (MPO) concentrations were also quantified in these homogenates by ELISA (Figure 2B). Intraocular concentrations of WT and 
$\triangle i n h A 1$ B. thuringiensis were significantly different at 6,8 , and 12 hours $(\mathrm{P}=0.0164,0.0359$, 0.0332, respectively). The in vitro growth differences of WT and $\Delta i n h A 1 B$. thuringiensis were reflected in vivo. MPO concentrations in the eyes infected with each strain were similar $(\mathrm{P} \geq$ 0.0829), suggesting similar levels of inflammation. Overall, these results suggested that despite better growth of the $\Delta i n h A l$ mutant, infection-related changes in eyes infected with either strain should be similar.

\section{Retinal Function is Not Preserved in the Absence of InhA1}

To determine if the absence of InhA1 altered retinal damage in endophthalmitis, we analyzed WT- and $\Delta i n h A 1$-infected mouse eyes using electroretinography (ERG). Figure 3 depicts retained A- and B-wave function and representative waveforms of infected eyes after 6, 8, 10, and 12 hours postinfection. The amplitude data indicated that retinal function in eyes infected with WT and $\operatorname{\Delta inhA1B}$. thuringiensis was similar from 6 to 10 hours postinfection $(\mathrm{P} \geq 0.2767$, Figure $3 \mathrm{~A}$ and Figure 3B). The function of retinal photoreceptor cells is represented by the A-wave function. Eyes infected with WT and $\triangle i n h A 1 B$. thuringiensis showed similar reductions in A-wave function until 12 hours postinfection $(\mathrm{P} \geq 0.2767$, Figure $3 \mathrm{~A})$. The $\mathrm{B}$-wave represents the function of rod bipolar cells, Muller cells, and second order neurons. At all time points, the B-wave function rapidly decreased in both WT and $\Delta i n h A 1$ B. thuringiensis-infected eyes ( $\mathrm{P} \geq 0.3022$, Figure 3B). The A-wave and B-wave retention responses declined to approximately $25 \%$ and $40 \%$ in eyes infected with WT or $\triangle i n h A 1$ B. thuringiensis, respectively, after 12 hours. Figure 3C shows representative waveforms, which demonstrate the rapid decrease of retinal function in both A- and B-waves at 12 hours postinfection. These results demonstrated that the retinal function of eyes infected with WT or $\triangle i n h A 1$ B. thuringiensis were similar, suggesting that the absence of InhA1 did not alter retinal function loss during experimental endophthalmitis.

\section{Absence of InhA1 Does Not Preserve Ocular Architecture}

The WT and $\Delta i n h A 1$ B. thuringiensis-infected eyes were harvested and fixed, sectioned, and stained with hematoxylin and eosin (Figure 4). At all time points, the ocular architecture in both WT and $\Delta$ inhAl $B$. thuringiensis-infected eyes were similar. Beginning at 8 hours 
186

187

188

189

190

191

192

193

194

195

196

197

198

199

200

201

202

203

204

205

206

207

208

209

210

211

212

213

214

postinfection, inflammatory cells entered the vitreous. At 10 hours postinfection, a significant amount of fibrin and inflammatory cells were observed in the vitreous. At 12 hours postinfection, severe inflammation, retinal detachment, and indistinguishable retinal layers were observed in the posterior segments of both WT and $\Delta i n h A 1$ B. thuringiensis-infected eyes. These results showed that an absence of InhA1 did not reduce the damage observed in Bacillus endophthalmitis. This further suggests that InhA1 alone did not contribute to the pathogenesis of Bacillus endophthalmitis.

\section{Absence of InhA2 in Bacillus Alters Growth}

Because InhA2 was also expressed in BHI, Luria-Bertani (LB) broth, and in Bacillus endophthalmitis-related environments [28-30], we also explored the contribution of this potential virulence factor. The growth and phenotypes of B. thuringiensis 407 (WT) and its isogenic InhA2deficient mutant $(\triangle i n h A 2)$ were compared. $\triangle i n h A 2$ had higher bacterial concentrations than WT at 2, 6, and 8 hours $(\mathrm{P}=0.0311,0.0160$, and 0.0075 , respectively) (Figure 5A). Figure 5B demonstrates that although the InhA2 mutant and WT had similar growth rates, the InhA2 mutant reached stationary phase 2 hours before the WT B. thuringiensis. $\triangle i n h A 2$ also entered $\log$ phase 2 hours before the WT strain. Figure 5C showed no significant differences in the hemolytic activity of WT and $\triangle i n h A 2 B$. thuringiensis supernatants from 18 hour cultures ( $\mathrm{P} \geq 0.9623)$. Cytotoxicity of human RPE was also similar between WT and $\triangle i n h A 2 B$. thuringiensis supernatants $(\mathrm{P}=$ 0.7931, Figure 5D), as was proteolytic activity $(\mathrm{P}=0.1359$, Figure $5 \mathrm{E})$. These results indicated that absence of InhA2 affected in vitro bacterial growth, but not proteolysis, hemolysis, or cytotoxicity. These results suggested that the intraocular growth of Bacillus lacking InhA2 might infect the mouse eye in a manner similar to that of the InhA1 mutant.

\section{Absence of InhA2 Increases Bacterial Burden But Not Inflammation in Endophthalmitis}

To determine if InhA2 contributed to intraocular growth and inflammation, the concentrations of bacteria and MPO were determined after $200 \mathrm{CFU}$ of WT or $\triangle i n h A 2 B$. thuringiensis were intravitreally injected into the eyes of mice. Figure 6A depicts the intraocular growth of WT and $\triangle i n h A 2 B$. thuringiensis at 6, 8, 10, and 12 hours postinfection. The $\triangle i n h A 2 B$. 
215

216

217

218

219

220

221

222

223

224

225

226

227

228

229

230

231

232

233

234

235

236

237

238

239

240

241

242

243

thuringiensis-infected eyes contained significantly more bacteria than WT-infected eyes at 6 and 12 hours postinfection ( $\mathrm{P}=0.0286$ and 0.0087 , respectively). Figure $6 \mathrm{~B}$ shows that the intraocular MPO concentration was similar between eyes infected with WT or $\Delta i n h A 2$ B. thuringiensis $(\mathrm{P} \geq$ 0.4480). These results confirmed that an absence of InhA2 reflected the bacterial growth observed in vitro as well as the intraocular growth of the $\triangle i n h A l B$. thuringiensis. These similarities suggested that the retinal changes in $\triangle i n h A 2 B$. thuringiensis-infected eyes might be similar to the retinal changes observed in $\triangle i n h A 1$ B. thuringiensis-infected eyes (Figure 2).

\section{Absence of InhA2 Does Not Affect Retinal Function}

Retinal function was analyzed in WT and $\triangle i n h A 2 B$. thuringiensis-infected mouse eyes (Figure 7). ERG data demonstrated that the A- and B-wave amplitudes of WT and $\Delta i n h A l B$. thuringiensis-infected eyes were similar from 6 to 12 hours postinfection $(P \geq 0.3660$, Figures 7A and $7 \mathrm{~B}$ ). Both the A- and B-wave retention responses rapidly decreased in WT and $\Delta i n h A 2 B$. thuringiensis-infected eyes. Figure 7C shows the similarities in representative waveforms of eyes infected with these strains. This observation highlights the rapid decrease of retinal function in eyes infected with either WT or $\triangle i n h A 2 B$. thuringiensis. Eyes infected with $\triangle i n h A 2 B$. thuringiensis had retinal function loss similar to that of $\Delta i n h A l$-infected and WT-infected eyes, suggesting that the absence of InhA1 or InhA2 alone did not affect retinal function loss during Bacillus endophthalmitis.

\section{Ocular Damage and Inflammation are Similar Between WT and $\Delta i n h A 2$ Strains}

To determine if InhA2 contributed to retinal damage, eyes infected with WT or $\triangle i n h A 2 B$. thuringiensis were harvested for histological analysis at 6, 8, 10, and 12 hours postinfection (Figure 8). At every time point, the ocular architecture in both WT and $\triangle i n h A 2 B$. thuringiensis-infected eyes was similar. At 8 hours postinfection, both WT and $\Delta i n h A 2 B$. thuringiensis-infected eyes were inflamed. After 12 hours postinfection, there was retinal detachment and deterioration of retinal layers in the posterior segment of both WT and $\Delta i n h A 2$ B. thuringiensis-infected eyes. These results showed that the absence of InhA2 alone, like the absence of InhA1 alone, did not alter the ocular damage observed in Bacillus endophthalmitis. 


\section{Compensation of InhA Expression in the Single InhA Mutants}

To understand the in vitro and in vivo results observed with the single InhA mutants, we sought to determine if the absence of one InhA affected the expression of other InhAs. Therefore, we analyzed the expression of inhA1, inhA2, and inhA3 in $\triangle i n h A 1$ and $\triangle i n h A 2 B$. thuringiensis. Additionally, the expression of all three inhAs were examined in $\Delta i n h A 1-3$ B. thuringiensis as a negative control. Expression in all mutants was compared to that of WT (Figure 9). The expression of $i n h A 2$ and $i n h A 3$ in the $\triangle i n h A 1$ strain was elevated, but not statistically significantly different from that of WT (Ct values, $\mathrm{P} \geq 0.3342$ ). The expression of $i n h A 1$ in the $\triangle i n h A 2$ strain was significantly greater than WT (Ct values, $\mathrm{P}=0.0036)$. The expression of $i n h A 3$ in the $\triangle i n h A 2$ strain was elevated, but not statistically significantly different from that of $\mathrm{WT}(\mathrm{Ct}$ values, $\mathrm{P}=0.1881)$. Overall, these results suggested that an absence of expression of a single inhA caused an elevated, although not always statistically significant, expression of the other inhAs. This potential compensation could explain why infections with $\triangle i n h A 1$ or $\triangle i n h A 2$ mutants were not different from WT infections, despite the differences in growth. To examine the role of InhAs as a whole in this disease, a Bacillus mutant lacking all three InhAs was tested in subsequent experiments.

\section{Absence of InhA1, InhA2, and InhA3 in Bacillus Alters Proteolysis}

To determine if all three Bacillus InhAs together were involved in the severity of Bacillus endophthalmitis, a strain lacking all three $\operatorname{InhAs}(\triangle \operatorname{Inh} A 1-3)$ was tested. Phenotypes of the $\Delta i n h A 1$ 3 strain were compared to that of its WT Bacillus parent strain (Figure 10). Unlike the single InhA mutants, the in vitro growth of $\mathrm{WT}$ and $\Delta i n h A 1-3$ in $\mathrm{BHI}$ was similar at every time point $(\mathrm{P} \geq$ 0.3586, Figure 10A). Figure 10B demonstrates that both strains had similar growth rates $(\mathrm{P}=$ 0.7220). Figure 10C shows similarities in hemolytic activities of the supernatants of $\triangle i n h A 1-3$ and the WT strain, except at the dilution of 1:32 $(\mathrm{P}=0.0001)$. Both strains had similar cytotoxicity against RPE cells $(\mathrm{P}=0.8250$, Figure 10D). The proteolytic zones of $\Delta$ inhA1-3 B. thuringiensis colonies were significantly smaller compared to that of WT colonies $(\mathrm{P}=0.0018$, Figure 10E). These results showed that an absence of all the InhAs did not affect bacterial growth, hemolysis, 
272 or cytotoxicity, but reduced proteolysis. Overall, the results suggested that the $\Delta$ InhAl-3 growth

273 might be similar to WT in vivo.

\section{Absence of InhAs 1, 2, and 3 Alters Intraocular Bacterial Burden and Inflammation}

Because preliminary data suggested that infections with the $\Delta i n h A 1-3$ would be less severe, intraocular growth and MPO concentrations were quantified in eyes infected with $\triangle i n h A 1-3$ after 12 hours. The intraocular bacterial concentrations of $\triangle i n h A 1-3$ B. thuringiensis were lower than that of WT, with significant differences at 12,14 , and 16 hours postinfection $(\mathrm{P}=0.0002,0.0022$, 0.0095, respectively, Figure 11A). At 16 hours postinfection, the concentrations $\Delta i n h A l-3 B$. infected eyes were also significantly lower compared to WT-infected eyes at 6, 10, and 14 hours postinfection $(\mathrm{P}=0.0079,0.0286,0.0022$, respectively, Figure 11B). These differences showed that an absence of all three InhAs resulted in a lower intraocular bacterial concentration that cleared approximately 16 hours postinfection. These differences suggested that the retinal function in DinhA1-3 B. thuringiensis-infected eyes should be preserved, compared with eyes infected with the WT strain.

\section{Retained Retinal Function in Eyes Infected with Bacillus Lacking all InhAs}

Retinal function analysis of mouse eyes infected with either WT or $\Delta i n h A 1-3 \quad B$. function. In Figure 12, ERGs depict retained retinal function in eyes infected with $\Delta i n h A l-3 B$. thuringiensis, which was significantly greater than that of WT-infected eyes at 12,14, and 16 hours postinfection for A-wave $(\mathrm{P} \leq 0.0358)$ and $\mathrm{B}$-wave $(\mathrm{P} \leq 0.0015)$. The photoreceptor function in DinhA1-3 B. thuringiensis-infected eyes was approximately $80 \%$ whereas WT-infected eyes had a photoreceptor function that decreased to approximately $40 \%$ at 16 hours postinfection (Figure $60 \%$, while function in the WT-infected eyes decreased to approximately $30 \%$ at 16 hours postinfection (Figure 12B). Figure 12C shows representative waveforms of WT and $\Delta i n h A 1-3 B$. 
301

302

303

304

305

306

307

308

309

310

311

312

313

314

315

316

317

318

319

320

321

322

323

324

325

326

327

328

329

in WT-infected eyes and retained amplitudes in $\triangle i n h A 1-3$ B. thuringiensis-infected eyes. This observation indicated that in the absence of InhA1, InhA2, and InhA3, retinal function during Bacillus endophthalmitis was preserved.

\section{Ocular Architecture is Preserved in the Absence of all InhAs}

Histology of WT or $\Delta i n h A 1-3$ B. thuringiensis-infected eyes is illustrated in Figure 13. Eyes were harvested for histology at 6, 8, 10, and 12 hours postinfection. Mouse eyes exhibited similar degrees of inflammation until 12 hours postinfection. At 12 hours postinfection, the WT eyes had retinal detachments and loss of retinal layers. However, the retinas of $\Delta i n h A 1-3 B$. thuringiensis-infected eyes were attached, and the layers of the retina were distinguishable. The $\Delta$ inhA1-3 B. thuringiensis-infected eyes had fibrin and inflammatory cells present in the vitreous at 12 hours postinfection, but to a lesser degree than that of WT-infected eyes. Together, these results demonstrated that the absence of all three InhAs (InhA1, InhA2, and InhA3) significantly reduced Bacillus virulence during intraocular infection.

\section{Discussion}

Bacillus is capable of producing a rapid and severe intraocular infection, which often results in loss of vision or the eye itself. During experimental endophthalmitis, Bacillus induces an explosive inflammatory response with vascular permeability and PMN infiltration into the vitreous beginning at approximately 4 hours postinfection [1,6]. This blood-retinal barrier permeability and neutrophil infiltration into a normally immune privileged environment is detrimental to vision. The immune response in the eye is tightly regulated -- the vitreous is avascular, there is a lack of lymphatic vessels and antigen presenting cells, and immunosuppressive factors are present [45-47]. Bacterial endophthalmitis and other ocular diseases with inflammation compromise immune privilege. A combination of toxin activities, the early innate immune response, and subsequent ocular damage during endophthalmitis allows the components of blood from the retinal vasculature enter the vitreous [20,21,48-52]. The retinal vascular permeability and PMN infiltration observed in Bacillus endophthalmitis is due, in part, to Bacillus virulence factors and their effect on ocular barrier cells, such as the RPE [20,21]. Identifying virulence factors that 
contribute to processes that result in compromised ocular clarity are of interest in understanding how Bacillus induces a rapid and severe disease.

Bacillus cereus sensu lato group species produce many virulence factors that may contribute to ocular inflammation and damage during Bacillus endophthalmitis [12,17-20,23,26]. For B. cereus and B. thuringiensis, a majority of these virulence factors are controlled by the pleotropic regulator of extracellular virulence, PlcR. We reported that in the absence of PlcRregulated toxin expression, Bacillus is capable of inducing inflammatory cell influx, blood retinal permeability, and retinal function loss in experimental endophthalmitis, albeit slower than that caused by WT Bacillus [19,21]. This suggests that virulence factors not regulated by PlcR contribute to intraocular infection as well.

To identify the specific virulence factors that contribute to Bacillus endophthalmitis, recent studies have observed molecular signatures and virulence factor gene expression in Bacillusinfected mouse eyes. In particular, the InhA metalloproteases of Bacillus are highly expressed in explanted vitreous [28] and are strongly associated with experimental Bacillus endophthalmitis $[29,30]$. The InhAs have a wide range of functions in many members of the Bacillus cereus sensu lato group. Originally identified for hydrolyzing insect antibacterial proteins [36], the InhA1 protein has now been demonstrated to be involved in autocleavage events which may contribute to Bacillus' ability to escape from host macrophages and modulate its own secretome [40,53]. InhA1 has been observed to contribute to blood-brain barrier permeability by degrading ZO-1 [37], a tight junction protein found in retinal barriers [20,21]. These studies highlight the potential importance of InhAs in infection, so we sought to determine their contribution to the severity of Bacillus endophthalmitis.

To ensure that the absence of InhAs did not affect hemolysis and cytotoxicity, we compared these activities in supernatants of InhA mutant and WT B. thuringiensis. The absence of InhA1 affected proteolysis, but not hemolysis or cytotoxicity. This was not the case for InhA2, since $\triangle i n h A 2 B$. thuringiensis was as proteolytic as WT. This result may have been attributed to the elevated expression of InhA1 and InhA3 in the $\triangle i n h A 2$ mutant compared to WT. Although InhA2 and InhA3 were expressed in the $\triangle i n h A 1$ mutant, the proteolysis of $\triangle i n h A 1 B$. thuringiensis was significantly less than WT. InhA1 has been shown to be important for degrading tight junction proteins, plasma, and matrix proteins [37,38,54]. Thus, InhA1 may be important for retinal 
vascular permeability and intraocular tissue destruction via degradation of tight junction and extracellular matrix protein during Bacillus endophthalmitis.

In this study, we investigated the effects of Bacillus thuringiensis InhA mutations on intraocular growth, inflammation, and retinal function during experimental Bacillus endophthalmitis. Our findings showed that the absence of single InhAs affected the expression of the other InhAs, and that bacterial growth in vitro was affected by the absence of InhA1 or InhA2, resulting in higher concentrations of bacteria beginning at the exponential phase of growth. A similar growth phenotype was observed in vivo during Bacillus endophthalmitis. This growth phenotype may be a consequence of the expression of other InhAs when one InhA is absent. Another possible explanation for this difference is that InhAs might affect bacterial physiology. We inoculated fresh media with stationary phase Bacillus, so Bacillus must re-enter the logarithmic state before multiplying. It is possible that the physiological state of the $\Delta i n h A l$ and $\triangle i n h A 2$ strains facilitated a faster switch to logarithmic phase after inoculation in fresh medium. The InhA metalloproteases are a part of the M6 evolutionary protein family, which has been identified in environmental genera such as Clostridioides, Geobacillus, Shewanella, and Vibrio [55]. This type of protease might contribute to environmental persistence, nutrient acquisition, and survival. In a study investigating bacterial zinc metalloproteases from Aeromonas salmonicida, protease-deficient A. almonicida strains had slower rates of bacterial growth in media with heatinactivated serum [56]. In untreated serum, the growth rates were quickly reduced in these mutants, suggesting that proteases play a critical role in the early stages of infection process by protecting bacteria against complement-mediated killing or other serum bactericidal effects. This also suggested that proteolytic activity might provide nutrients for continued growth and proliferation. A similar phenomenon may be at play in this study, in which a mutant lacking all three InhAs is unable to provide nutrients in the vitreous for patterns of growth similar to wild type, leading to clearance starting at 12 hours postinfection. The $\Delta i n h A l-3$ strain may have grown similar to WT in vitro because of the readily available nutrients in the BHI medium. The growth effects in the single mutants may be explained by the availability of nutrients via expression of the other InhAs. Bacillus may utilize these InhAs to prolong survival in the ocular environment by degrading proteins, such as collagen fibers of types II, V, IX and XI in the vitreous. In the absence of the three InhAs, Bacillus may not have been able to degrade these proteins, and the lack of nutrient availability resulted in a lower burden that was more easily cleared. 
The inflammatory response in eyes infected with $\triangle i n h A 1$ or $\triangle i n h A 2$ was similar to that seen in WT-infected eyes. These observations were unexpected considering the increased intraocular growth of the single mutants compared to WT. In eyes infected with Bacillus lacking InhAs 1, 2, and 3, the inflammatory response was delayed. These observations may have been due to the compensating expression of the other InhAs in the single mutants, which may have facilitated growth to concentrations which triggered the activation of innate immune pathways, blood-retinal barrier permeability, and PMN infiltration [57,58]. This effect may have been similar to how B. anthracis InhA contributes to breakdown of blood-brain barriers via degradation of ZO1 , leading to inflammatory cell infiltration and hemorrhaging in the mouse brain [37]. We reported that B. cereus-infected eyes have little to no expression of ZO-1 in the RPE at 12 hours postinfection [21]. Also, when injected into mouse eyes, WT B. cereus and $\Delta p l c R$ B. cereus supernatants induced permeability of the blood ocular barrier [21]. Therefore, secreted InhAs may contribute to the degrading of $\mathrm{ZO}-1$ and permeability of the blood-retinal barriers, leading to infiltration of PMNs into the vitreous. PMN are the first and most abundant inflammatory cells infiltrating into the eye during B. cereus endophthalmitis [1,6]. These cells are capable of phagocytosing $B$. cereus in vitro [57]. InhA1 has been shown to be important for allowing $B$. cereus to escape from macrophages [40]. Whether the InhAs are important in protecting Bacillus from PMN-mediated killing in the eye is an open question.

Both bacteria and the inflammatory response contribute to retinal damage. Damage to retinal cells and tissues may result in substantial and permanent vision loss, which is typical for Bacillus endophthalmitis [9-11]. Because the expression of InhA has been associated with Bacillus ocular infection in mice, and in toxicity in other models, we evaluated retinal function in eyes infected with WT or $\Delta \mathrm{i} n h A 1, \Delta i n h A 2$, or $\Delta i n h A 1-3$ B. thuringiensis. The absence of all three InhAs protected the eyes from retinal function loss, which would be expected in eyes with intact retinal structure and minimal inflammation (Figures 4, 8, and 12). Because WT and $\Delta i n h A l-3$ B.

417 damage in vivo may not have been due to differences in the production of other toxins by these 418 strains. Instead, these differences may correspond with the decreased bacterial growth and delayed 419 inflammation in eyes infected with the strain lacking the InhA metalloproteases. As previously mentioned, the InhAs may have a role in growth via nutrient acquisition from the surrounding 
421 environment, which could explain the triple mutant's delayed growth in vivo, and, subsequently,

422 its attenuated retinal damage and inflammation.

423

424

425

426

427

428

429

430

431

432

433

434

435

436

437

438

439

440

441

442

443

444

445

446

This study is the first to address the importance of the Bacillus metalloproteases in an experimental intraocular eye infection, which mimics human infection. We demonstrated that a deficiency in Bacillus InhAs resulted in an attenuated intraocular infection. Our findings suggest that the InhAs may facilitate intraocular bacterial growth by producing an environment more conducive to persistence. Current therapeutics are relatively ineffective in treating Bacillus endophthalmitis [1,9-11,59-63], and due to its rapidly blinding course, Bacillus endophthalmitis requires early and precise treatment [62,63]. Treatment strategies for Bacillus and other types of endophthalmitis should be based on knowledge of the virulence factors that contribute to disease pathogenesis. Therefore, these metalloproteases may prove to be ideal targets for therapeutics in this potentially blinding disease.

\section{Materials and Methods}

\section{Ethics Statement}

The described experiments were conducted following the guidelines in the Guide for the Care and Use of Laboratory Animals, the Association for Research in Vision and Ophthalmology Statement for the Use of Animals in Ophthalmic and Vision Research, and the University of Oklahoma Health Sciences Center Institutional Animal Care and Use Committee (approved protocol 18-043).

\section{Bacterial Strains}

B. thuringiensis 407 (WT) or its isogenic InhA mutants ( $\triangle i n h A 1, \Delta i n h A 2, \Delta i n h A 1-3)$ [35,64] were injected into mouse eyes, as previously described [2,6,21,23,26,65,65-67]. Phenotypes of WT, $\triangle i n h A 1, \triangle i n h A 2$, and $\triangle i n h A 1-3$ B. thuringiensis were compared by quantifying growth, hemolysis, cytotoxicity, and proteolysis, as described below. 


\section{Bacterial Growth Curves}

All strains were cultured for 10 hours with aeration at $37^{\circ} \mathrm{C}$ in brain heart infusion $(\mathrm{BHI}$; VWR, Radnor, PA, USA) medium. Strains were diluted in fresh BHI to approximately $10^{5}$ $\mathrm{CFU} / \mathrm{mL}$ and incubated for an additional 10 hours. Every 2 hours, $20-\mu \mathrm{L}$ aliquots were track diluted in PBS and plated onto BHI agar plates, and counted after 24 hours [2,6,21,23,26,65,6567]. Growth rates were analyzed by the equation, $N_{t}=N_{0} \times(1+r)^{t}$, where $\mathrm{N}_{\mathrm{t}}$ is the concentration of bacteria at the end time, $\mathrm{N}_{0}$ is the concentration of bacteria at the initial time, $\mathrm{r}$ is the growth rate, and $\mathrm{t}$ is the time passed.

\section{Hemolytic Analysis}

WT and $\sinh A B$. thuringiensis were each cultured as described above, then centrifuged at $4150 \mathrm{rpm}$ for 10 minutes. Supernatants were removed and filter sterilized $(0.22 \mu \mathrm{m}$; Millex-GP, Merck Millipore Ltd., Cork, Ireland) and diluted two-fold in PBS (pH 7.4). Dilutions were incubated 1:1 with 4\% (vol/vol) sheep red blood cells (Rockland Immunochemicals, Pottstown, PA, USA) in a round-bottom microtiter plate for 30 minutes at $37^{\circ} \mathrm{C}$. After centrifugation at 300

$463 \mathrm{x} g$ for 10 minutes, supernatants were transferred into a flat-bottom microtiter plate and hemoglobin release was quantified (490 nm, FLUOstar Omega, BMG Labtech, Cary, NC, USA).

465 Values are expressed in percent hemolysis relative to a 100\% lysis control, as previously described $466 \quad[16,19,26,61,68]$.Values represent the means \pm SD of two independent experiments.

\section{Retinal Pigment Epithelial Cell Cytotoxicity}

Human ARPE-19 cells (American Type Culture Collection, Manassas, VA, USA) were grown to confluence in culture medium (DMEM/F12 supplemented with $10 \%$ fetal bovine serum and 1\% glutamine; Gibco, Grand Island, NY, USA), diluted, and seeded into sterile 24-well plates.

472 Twenty-thousand cells/100 $\mu \mathrm{L}$ were seeded in triplicate wells for overnight incubation.

473 Supernatants of WT and $\triangle i n h A B$. thuringiensis were generated as described above, diluted 1:2, and added to wells containing ARPE-19. Cytotoxicity was measured by quantifying lactate 
475

476

477

478

479

480

481

482

483

484

485

486

487

488

489

490

491

492

493

494

495

496

497

498

499

500

501

502

dehydrogenase (LDH) from ARPE-19 (Pierce LDH Cytotoxicity Assay Kit, ThermoFisher Scientific, Waltham, MA, USA), according to the manufacturer's instructions [12,20].

\section{Proteolytic Activity Assay}

Protease production of WT and $\triangle i n h A B$. thuringiensis was detected on skim milk agar plates (CRITERION ${ }^{\mathrm{TM}}$; Hardy Diagnostics, Santa Maria, CA, USA). Colonies were transferred to the skim milk agar plates using a sterile toothpick and were incubated at $37^{\circ} \mathrm{C}$ for $48 \mathrm{~h}$. Clear zones with at least $1 \mathrm{~mm}$ around single colonies indicated the activity of secreted proteases capable of hydrolyzing casein. Proteolytic zones were measured in millimeters from the edge of the colony to the edge of the clear zone.

\section{Mice and Intraocular Infections}

In vivo experiments used mice (C57BL/6J, stock No. 000664; Jackson Labs, Bar Harbor, ME, USA). Mice were housed on a 12-hour light/dark cycle, for at least 2 weeks to equilibrate their microbiota, and under biosafety level 2 conditions. Mice (8-10 weeks old) were sedated with a cocktail of ketamine $(85 \mathrm{mg} / \mathrm{kg}$ body weight; Ketathesia, Henry Schein Animal Health, Dublin, OH, USA) and xylazine (14 mg/kg body weight; AnaSed; Akorn Inc., Decatur, IL, USA). Deep anesthesia was confirmed by toe pinch. Infections were initiated by intravitreal injection containing $\sim 200 \mathrm{CFU}$ WT or $\triangle i n h A B$. thuringiensis in $0.5 \mu \mathrm{L}$ BHI using a sterile glass capillary needle, as previously described [2,6,21,23,26,65,65-67]. Uninjected fellow eyes served as controls. As described below, eyes were analyzed by electroretinography (ERG) prior to euthanasia. After euthanasia $\left(\mathrm{CO}_{2}\right.$ inhalation), eyes were harvested and infection courses were analyzed by quantifying intraocular Bacillus and polymorphonuclear leukocyte (PMN) infiltration (myeloperoxidase [MPO] activity), and histology.

\section{Quantifying Intraocular Bacterial Growth}

Intraocular Bacillus were quantified from harvested eyes at 0, 2, 6, 8, 10, 12, 14, and 16 hours postinfection. Harvested eyes were homogenized in $400 \mu \mathrm{L}$ PBS containing sterile glass 
503 beads ( $1 \mathrm{~mm}$; BioSpec Products, Inc., Bartlesville, OK, USA). Eye homogenates were then track

504 diluted onto BHI agar and counted, as previously described [2,6,21,23,26,65,65-67].

505

506

\section{Electroretinography}

507

508

ERG was used to quantify retinal function in eyes infected with WT or $\triangle i n h A B$. thuringiensis, as previously described [2,6,21,23,26,65,65-67]. Scotopic ERGs were performed at 6, 8, 10, 12, 14, and 16 hours postinfection using Espion E2 software (Diagnosys LLC, Lowell, MA, USA). Mice were dark-adapted for at least 6 hours prior to ERG. Mice were anesthetized as noted above, and pupils were topically dilated (Phenylephrine $\mathrm{HCl} 2.5 \%$; Akorn, Inc.). Two gold wire electrodes were placed on each cornea and reference electrodes were place on the forehead and tail. Eyes were then stimulated by five flashes of white light $\left(1200 \mathrm{~cd} \cdot \mathrm{s} / \mathrm{m}^{2}\right)$. A- and B-wave amplitudes were recorded for both eyes in the same animal. The percentage of retinal function retained was calculated using the formula $100-\{[1-$ (experimental A-wave amplitude/control A517 amplitude)] $\mathrm{x} 100\}$.

\section{Histology}

For histology, eyes were harvested from euthanized mice at 6, 8, 10, and 12 hours postinfection, incubated in low-alcoholic fixative for 30 minutes, and transferred to $70 \%$ ethanol

522 for at least 24 hours. Paraffin-embedded eyes were sectioned and stained with hematoxylin and $\operatorname{eosin}[2,6,21,23,26,65,65-67]$.

\section{Estimation of Inflammatory Cell Influx}

PMN infiltration into eyes was estimated by quantifying MPO using a sandwich ELISA

527 (Hycult Biotech, Plymouth Meeting, PA, USA) as previously described [6,27,65,66]. Eyes were harvested at 6, 8, 10, and 12 hours postinfection, transferred into PBS-containing proteinase inhibitor (Roche Diagnostics, Indianapolis, IN, USA), and homogenized using sterile glass beads 
Table 1. Primers Used in Quantitative PCR

\begin{tabular}{ll}
\hline Gene & Sequences $\left(5^{\prime} \rightarrow 3^{\prime}\right)$ \\
\hline \multirow{2}{*}{$i n h A 1$} & AGA AGA TGG AGC GGT TGG TG \\
& AAT CGG CTC ACC TTG ACC AC \\
\hline \multirow{2}{*}{$i n h A 2$} & GTG GAG GTA GTT GA CAG GG \\
& GCC CAG TTG CCA CCC ATA TT \\
\multirow{2}{*}{$i n h A 3$} & GCG TTA CAA CAT GCA CGT GG \\
\hline \multirow{2}{*}{16 s rRNA } & CAC CTG GAT GAA CGC CTA CC \\
& GGC GCG AAA GCG TGG GGA GC \\
& CAG CAC TAA AGG GCG GAA AC \\
\hline
\end{tabular}
detection for this assay was $2 \mathrm{ng} / \mathrm{mL}$.

\section{RNA Isolation and Quantitative PCR}

Expression of immune inhibitor A metalloprotease (InhA1, InhA2, and InhA3) genes from WT or $\triangle i n h A B$. thuringiensis was measured by real-time quantitative PCR (rtQPCR). Strains were grown in BHI. Total RNA was isolated from 18-hour cultures (RNeasy Mini Kit; QIAGEN, Hilden, Germany), DNA was removed (TURBO DNA-free Kit; Invitrogen, Carlsbad, CA, USA), and RNA was purified (RNA Clean \& Concentrator-5 Kit; Zymo Research, Irvine, CA, USA), all following kit manufacturer's instructions. RNA purity and concentration was confirmed using a Nanodrop (ThermoFisher). rtQPCR was performed (Applied BioSystems 7500; ThermoFisher), using the iTaq Universal SYBR Green One-Step Kit (Bio-Rad, Hercules, CA, USA) and primers listed in Table 1. Amplifications were performed in triplicate. Relative gene expression was determined using the $\triangle \mathrm{CT}$ method, using $16 \mathrm{~S}$ rRNA as a reference housekeeping gene.

\section{Statistics}

Mann-Whitney U test was used for statistical comparisons unless otherwise specified

549 (GraphPad Prism 7 Software, Inc., La Jolla, CA, USA) [26,66,68]. P values of < 0.05 were considered significant. 


\section{Acknowledgements}

552 The authors thank Dr. Feng Li and Mark Dittmar (OUHSC Vision P30 Live Animal 553 Imaging and Analysis Core, Manali Kamath and Wil Nightengale for assistance with RNA 554 preparations and myeloperoxidase experiments. Dean A. McGee Eye Institute, Oklahoma City, 555 OK, USA) for invaluable technical assistance, and Excalibur Pathology (Moore, OK, USA) and 556 the OUHSC P30 Cellular Imaging Core (Dean A. McGee Eye Institute, Oklahoma City, OK, USA) 557 for histology expertise. This work was presented in part at the Association for Research in Vision 558 and Ophthalmology Annual Meeting 2019, Vancouver BC and at the Society for Leukocyte 559 Biology Annual Meeting 2019, Boston MA.

560

This work was supported by National Institutes of Health grants R01EY028810 and 561 R01EY024140 (to MCC). Our research was also supported in part by National Institutes of Health 562 grants R01EY025947 and R21EY028066 (to MCC), National Eye Institute Vision Core Grant 563 P30EY021725 (to MCC), a Presbyterian Health Foundation Research Support Grant Award (to 564 MCC and MHM), a Presbyterian Health Foundation Equipment Grant (to Robert E. Anderson, 565 OUHSC), and an unrestricted grant to the Dean A. McGee Eye Institute from Research to Prevent 566 Blindness. 


\section{References}

1. Livingston ET, Mursalin MH, Callegan MC. A pyrrhic victory: The PMN response to ocular bacterial infections. Microorganisms. 2019 Nov 7;7(11):537.

2. Mursalin MH, Livingston ET, Callegan MC. The cereus matter of Bacillus endophthalmitis. Exp Eye Res. 2020;193:107959.

3. Callegan MC, Engelbert M, Parke DW, Jett BD, Gilmore MS. Bacterial Endophthalmitis: Epidemiology, Therapeutics, and Bacterium-Host Interactions. 2002;15(1):111-24.

4. Parkunan SM, Callegan MC. The Pathogenesis of Bacterial Endophthalmitis. In: Durand ML, editor. Endophthalmitis. Springer International Publishing Switzerland; 2016. p. 1747.

5. Callegan MC, Booth MC, Jett BD, Gilmore MS. Pathogenesis of Gram-Positive Bacterial Endophthalmitis. Infect Immun. 1999;67(7): 3348-56.

6. Ramadan RT, Ramirez R, Novosad BD, Callegan MC. Acute inflammation and loss of retinal architecture and function during experimental Bacillus endophthalmitis. Curr Eye Res. 2006;31(11):955-65.

7. Bhagat N, Nagori S, Zarbin M. Post-traumatic Infectious Endophthalmitis. Surv Ophthalmol. 2011;56(3):214-51.

8. Nicoare SD, Irimescu I, Celinici T, Cristian C. Outcome and Prognostic Factors for Traumatic Endophthalmitis over a 5-Year Period. J Ophthalmol. 2015;2014;1-7.

9. David DB, Kirkby GR, Noble BA. Bacillus cereus endophthalmitis. Br J Ophthalmol. 1994;78:577-80.

10. Davey RT, Tauber WB. Posttraumatic endophthalmitis: the emerging role of Bacillus cereus infection. Rev Infect Dis. 9(1):110-23.

11. Vahey JB, Flynn HW. Results in the management of bacillus endophthalmitis. Ophthalmic Surg. 1991;22(11):681-6.

12. Callegan MC, Cochran DC, Kane ST, Ramadan RT, Chodosh J, McLean C, et al. Virulence factor profiles and antimicrobial susceptibilities of ocular Bacillus isolates. Curr Eye Res. 2006;31(9):693-702.

13. Maughan H, Van der Auwera G. Bacillus taxonomy in the genomic era finds phenotypes to be essential though often misleading. Infect Genet Evol. 2011;11(5):789-97.

14. Helgason E, Økstad OA, Caugant DA, Johansen HA, Fouet A, Mock M, et al. Bacillus anthracis, Bacillus cereus, and bacillus thuringiensis - One species on the basis of genetic evidence. Appl Environ Microbiol. 2000;66(6):2627-30.

15. Cho SH, Kang SH, Lee YE, Kim SJ, Yoo Y Bin, Bak YS, et al. Distribution of toxin genes and enterotoxins in Bacillus thuringiensis isolated from microbial insecticide products. J Microbiol Biotechnol. 2015;25(12):2043-8.

16. Callegan MC, Kane ST, Cochran DC, Novosad B, Gilmore MS, Gominet M, et al. Bacillus endophthalmitis: Roles of bacterial toxins and motility during infection. Investig Ophthalmol Vis Sci. 2005;46(9):3233-8. 
17. Callegan MC, Cochran DC, Kane ST, Gilmore MS, Gominet M, Lereclus D. Contribution of membrane-damaging toxins to Bacillus endophthalmitis pathogenesis. Infect Immun. 2002;70(10):5381-9.

18. Callegan MC, Jett BD, Hancock LE, Gilmore MS. Role of hemolysin BL in the pathogenesis of extraintestinal Bacillus cereus infection assessed in an endophthalmitis model. Infect Immun. 1999;67(7):3357-66.

19. Callegan MC, Kane ST, Cochran DC, Gilmore MS, Gominet M, Lereclus D. Relationship of plcR-regulated factors to Bacillus endophthalmitis virulence. Infect Immun. 2003;71(6):3116-24.

20. Moyer A, Ramadan R, Thurman J, Burroughs A, Callegan M. Bacillus cereus induces permeability of an in vitro blood-retina barrier. Infect Immun. 2008;76(4):1358-67.

21. Moyer A, Ramadan R, Novosad B, Astley R, Callegan M. Bacillus cereus Induces Permeability of the Blood Ocular Barrier During Experimental Endophthalmitis. Invest Ophthalmol Vis Sci. 2009;50(8):3783-93.

22. Mursalin MH, Coburn PS, Livingston E, Miller FC, Astley R, Flores-Mireles AL, et al. Bacillus S-Layer-Mediated Innate Interactions During Endophthalmitis. Front Immunol. 2020;11(215):1-16.

23. Mursalin MH, Coburn PS, Livingston E, Miller FC, Astley R, Fouet A, et al. S-layer Impacts the Virulence of Bacillus in Endophthalmitis. Investig Opthalmology Vis Sci. 2019 Sep 3;60(12):3727.

24. Clair G, Roussi S, Armengaud J, Duport C. Expanding the known repertoire of virulence factors produced by Bacillus cereus through early secretome profiling in three redox conditions. Mol Cell Proteomics. 2010 Jul;9(7):1486-8.

25. Gohar M, Faegri K, Perchat S, Ravnum S, Økstad OA, Gominet M, et al. The PlcR virulence regulon of Bacillus cereus. PLoS One. 2008;3(7):1-9.

26. Callegan MC, Parkunan SM, Randall CB, Coburn PS, Miller FC, LaGrow AL, et al. The role of pili in Bacillus cereus intraocular infection. Exp Eye Res. 2017;159:69-76.

27. Parkunan SM, Astley R, Callegan MC. Role of TLR5 and flagella in Bacillus intraocular infection. PLoS One. 2014;9(6).

28. Coburn PS, Miller FC, Enty MA, Land C, LaGrow AL, Mursalin MH, et al. Expression of Bacillus cereus Virulence-Related Genes in an Ocular Infection-Related Environment. Microorganisms. 2020;8(607):1-18.

29. Coburn PS, Miller FC, Enty MA, Land C, LaGrow AL, Mursalin MH, et al. The Bacillus virulome in endophthalmitis. BioRxiv doi: https://doi.org/10.1101/2020.07.02.184630

30. Yuan J, Li Y-Y, Xu Y, Sun B-J, Shao J, Zhang D, et al. Molecular Signatures Related to the Virulence of Bacillus cereus Sensu Lato, a Leading Cause of Devastating Endophthalmitis. mSystems. 2019;4(6):1-12

31. Lövgren A, Zhang M, Engström A, Dalhammar G, Landén R. Molecular characterization of immune inhibitor A, a secreted virulence protease from Bacillus thuringiensis. Mol Microbiol. 1990;4(12):2137-46. 
32. Ogierman MA, Fallarino A, Riess T, Williams SG, Attridge SR, Manning PA. Characterization of the Vibrio cholerae El Tor lipase operon lipAB and a protease gene downstream of the hly region. J Bacteriol. 1997;179(22):7072-80.

33. Charlton S, Moir A, Baillie L, Moir A. Characterization of the exosporium of Bacillus cereus. J Appl Microbiol. 1999;87(2):241-5.

34. Hoch JA. Regulation of the onset of the stationary phase and sporulation in Bacillus subtilis. Vol. 35, Advances in Microbial Physiology. Academic Press; 1993. p. 111-33.

35. Grandvalet C, Gominet M, Lereclus D. Identification of genes involved in the activation of the Bacillus thuringiensis inhA metalloprotease gene at the onset of sporulation. Microbiology. 2001;147:1805-13.

36. Dalhammar G, Steiner H. Characterization of inhibitor A, a protease from Bacillus thuringiensis which degrades attacins and cecropins, two classes of antibacterial proteins in insects. Eur J Biochem. 1984;139(2):247-52.

37. Mukherjee D, Tonry J, Kim KS, Ramarao N, Popova T, Bailey C, et al. Bacillus anthracis protease InhA increases blood-brain barrier permeability and contributes to cerebral hemorrhages. PLoS One. 2011;6(3):1-11.

38. Chung MC, Popova T, Millis B, Mukherjee D, Zhou W, Liotta L, et al. Secreted neutral metalloproteases of Bacillus anthracis as candidate pathogenic factors. J Biol Chem. 2006 Oct 20;281(42):31408-18.

39. Pflughoeft KJ, Swick MC, Engler DA, Yeo H-J, Koehler TM. Modulation of the Bacillus anthracis Secretome by the Immune Inhibitor A1 Protease. J Bacteriol. 2014;196:424-35.

40. Ramarao N, Lereclus D. The InhA1 metalloprotease allows spores of the B. cereus group to escape macrophages. Cell Microbiol. 2005;7(9):1357-64.

41. Haydar A, Tran S-L, Guillemet E, Darrigo C, Perchat S, Lereclus D, et al. InhA1Mediated Cleavage of the Metalloprotease NprA Allows Bacillus cereus to Escape From Macrophages. Front Microbiol. 2018;9(1063):1-10.

42. Fedhila S, Nel P, Lereclus D. The InhA2 Metalloprotease of Bacillus thuringiensis Strain 407 Is Required for Pathogenicity in Insects Infected via the Oral Route. J Bacteriol. 2002;184(12):3296-304.

43. Fedhila S, Gohar M, Slamti L, Nel P, Lereclus D. The Bacillus thuringiensis PlcRregulated gene inhA2 is necessary, but not sufficient, for virulence. J Bacteriol. 2003;185(9):2820-5.

44. Dubois T, Faegri K, Perchat S, Lemy C, Buisson C, Nielsen-LeRoux C, et al. Necrotrophism is a Quorum-sensing-regulated lifestyle in Bacillus thuringiensis. PLoS Pathog. 2012;8(4):1-10.

45. Streilein JW. Ocular immune privilege: Therapeutic opportunities from an experiment of nature. Nat Rev Immunol. 2003;3(11):879-89.

46. Sonoda KH, Sakamoto T, Qiao H, Hisatomi T, Oshima T, Tsutsumi-Miyahara C, et al. The analysis of systemic tolerance elicited by antigen inoculation into the vitreous cavity: Vitreous cavity-associated immune deviation. Immunology. 2005;116(3):390-9. 
47. Taylor AW, Ng TF. Negative regulators that mediate ocular immune privilege. J Leukoc Biol. 2018;10.1002/JLB.3MIR0817-337R.

48. Coburn PS, Wiskur BJ, Astley RA, Callegan MC. Blood-retinal barrier compromise and endogenous Staphylococcus aureus endophthalmitis. Investig Ophthalmol Vis Sci. 2015;56(12):7303-11.

49. Cousins SW, Guss RB, Howes EL, Rosenbaum JT. Endotoxin-induced uveitis in the rat: Observations on altered vascular permeability, clinical findings, and histology. Exp Eye Res. 1984;39(5):665-76.

50. Antonetti DA, Barber AJ, Khin S, Lieth E, Tarbell JM, Gardner TW. Vascular permeability in experimental diabetes is associated with reduced endothelial occludin content. Vascular endothelial growth factor decreases occludin in retinal endothelial cells. Diabetes. 1998;47(12):1953-9.

51. Natarajan S. Anti-vascular endothelial growth factor in age-related macular degeneration: Puzzle or a silent beginning! Indian J Ophthalmol. 2013;61(9):475-8.

52. Kumar A, Kumar A. Role of Staphylococcus aureus Virulence Factors in Inducing Inflammation and Vascular Permeability in a Mouse Model of Bacterial Endophthalmitis. PLoS One. 2015;10(6):1-17.

53. Kastrup CJ, Boedicker JQ, Pomerantsev AP, Moayeri M, Bian Y, Pompano RR, et al. Spatial localization of bacteria controls coagulation of human blood by "quorum acting". Nat Chem Biol. 2008 Dec;4(12):742-50.

54. Rawlings ND. MEROPS: the peptidase database. Nucleic Acids Res. 2006;34(90001):D270-2.

55. Leung K, Stevenson R. Tn5-Induced Protease-Deficient Strains of Aeromonas hydrophila with Reduced Virulence for Fish. Infect Immun. 1988;56(10):2639-44.

56. Murthy KR, Goel R, Subbannayya Y, Jacob H, Murthy PR, Manda SS, et al. Proteomic analysis of human vitreous humor. Clin Proteomics. 2014;11(1):29.

57. Parkunan SM, Randall CB, Coburn PS, Astley RA, Staats RL, Callegana MC. Unexpected roles for toll-like receptor 4 and TRIF in intraocular infection with grampositive bacteria. Infect Immun. 2015;83(10):3926-36.

58. Novosad BD, Astley RA, Callegan MC. Role of toll-like receptor (TLR) 2 in experimental Bacillus cereus endophthalmitis. PLoS One. 2011;6(12):e28619.

59. Astley RA, Coburn PS, Parkunan SM, Callegan MC. Modeling Intraocular Bacterial Infections. Prog Retin Eye Res. 2016;54:30-48.

60. Miller FC, Coburn PS, Huzzatul MM, LaGrow AL, Livingston E, Callegan MC. Targets of immunomodulation in bacterial endophthalmitis. Prog Retin Eye Res. 2019;73:100763.

61. Coburn PS, Miller FC, LaGrow AL, Land C, Mursalin H, Livingston E, et al. Disarming pore-forming toxins with biomimetic nanosponges in intraocular infections. mSphere. 2019;4(3):e00262-19. 
of vitrectomy in improving the outcome of Bacillus cereus endophthalmitis. Retina. 2011 Sep;31(8):1518-24.

63. Wiskur BJ, Robinson ML, Farrand AJ, Novosad BD, Callegan MC. Toward improving therapeutic regimens for bacillus endophthalmitis. Investig Ophthalmol Vis Sci. 2008;49(4):1480-7.

64. Guillemet E, Cadot C, Tran SL, Guinebretière MH, Lereclus D, Ramarao N. The InhA metalloproteases of Bacillus cereus contribute concomitantly to virulence. J Bacteriol. 2010;192(1):286-94.

65. Callegan MC, Gilmore MS, Gregory M, Ramadan RT, Wiskur BJ, Moyer AL, et al. Bacterial endophthalmitis: therapeutic challenges and host-pathogen interactions. Prog Retin Eye Res. 2007;26(2):189-203.

66. Parkunan SM, Randall CB, Astley RA, Furtado GC, Lira SA, Callegan MC. CXCL1, but not IL-6, significantly impacts intraocular inflammation during infection. J Leukoc Biol. 2016;100(5):1125-34.

67. Coburn PS, Miller FC, LaGrow AL, Parkunan SM, Randall C, Staats RL, et al. TLR4 modulates inflammatory gene targets in the retina during Bacillus cereus endophthalmitis. BMC Ophthalmol. 2018;18(1):96. Biomimetic Nanosponge Protects the Retina from the Enterococcus faecalis Cytolysin. mSphere. 2017;2(6):e00335-17. 
$749 \quad$ Figure 1

A

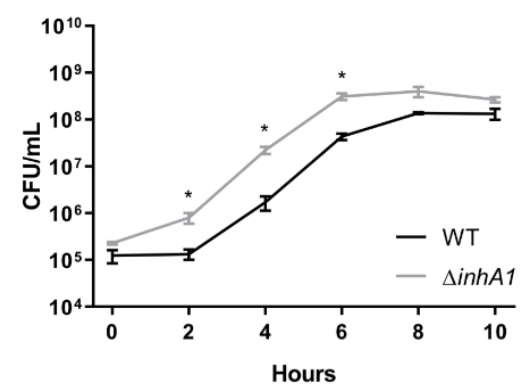

D

750

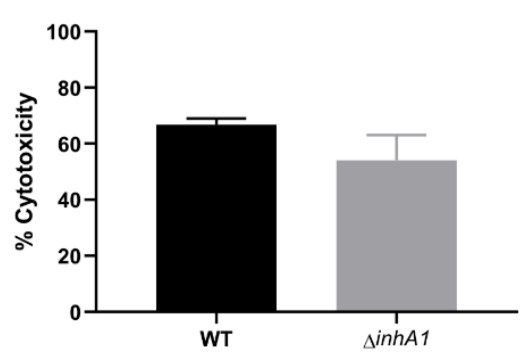

B

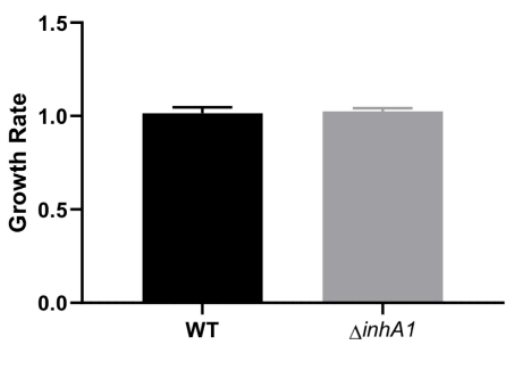

E

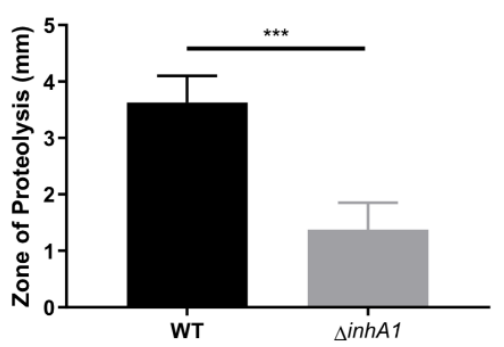

C

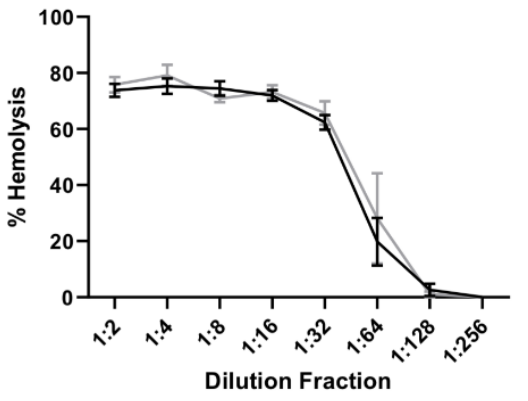

751 
764 Figure 2

A

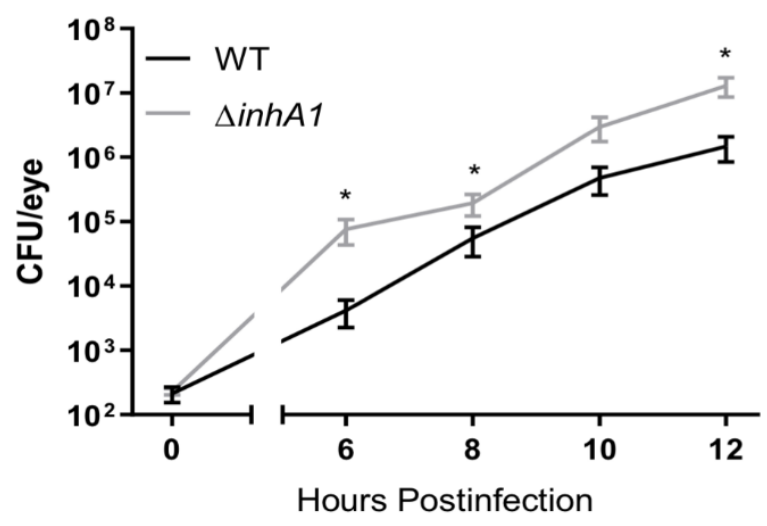

B

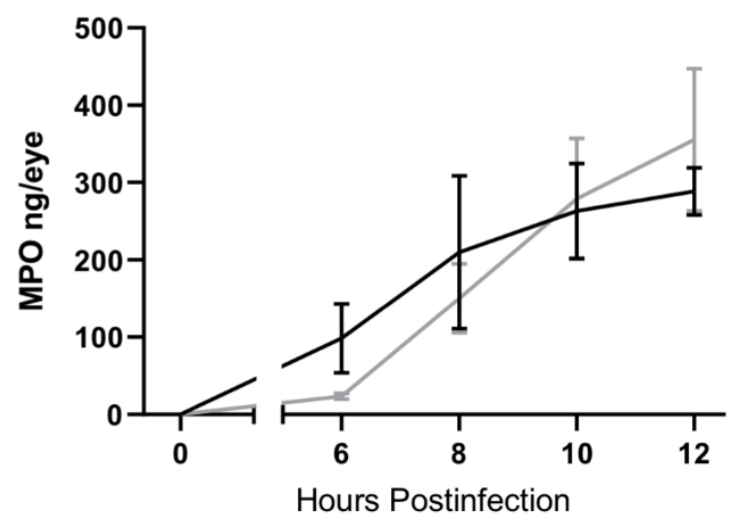

765

766

767

768

769

770

771

772

773

774

775

776

777

778

779 
781 Figure 3

A

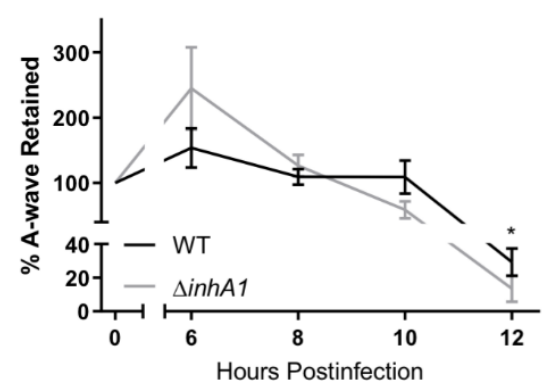

C

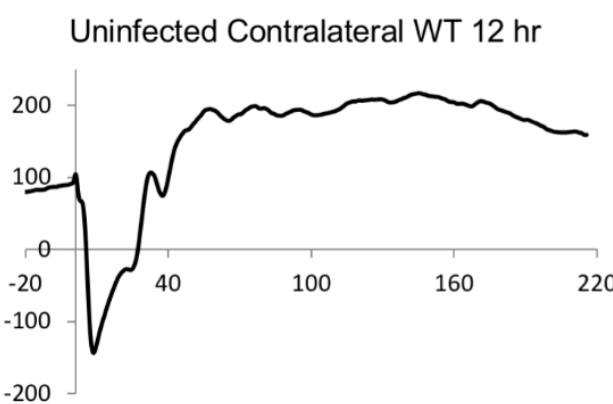

Uninfected Contralateral $\triangle i n h A 112 \mathrm{hr}$

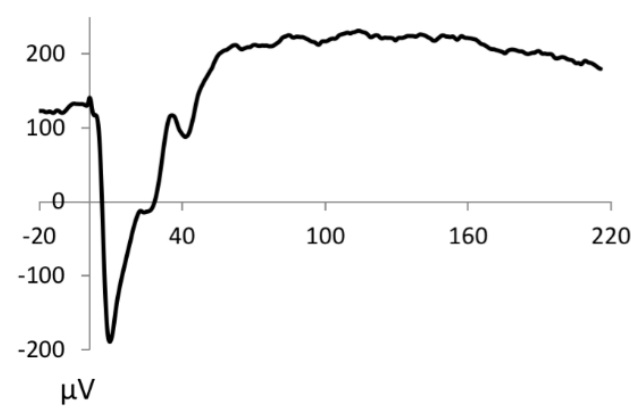

B

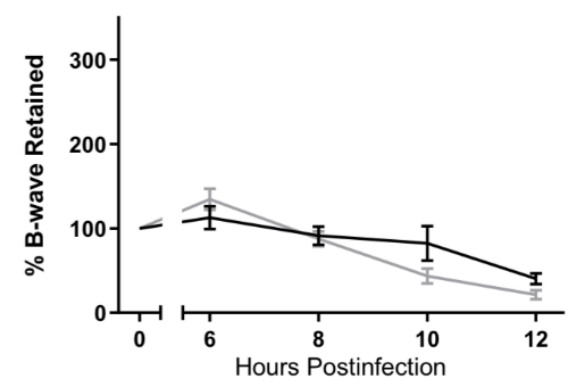

Infected WT $12 \mathrm{hr}$

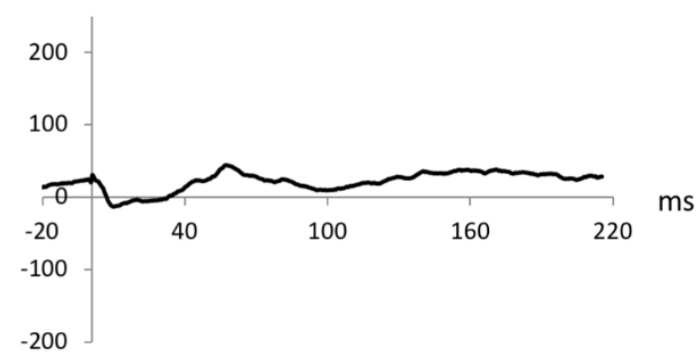

Infected $\Delta i n h A 112 \mathrm{hr}$

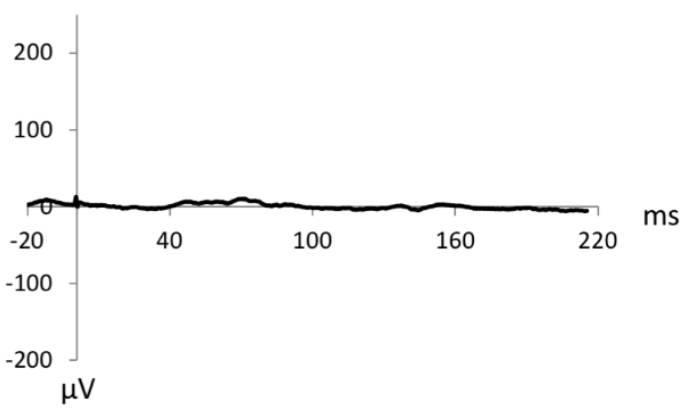



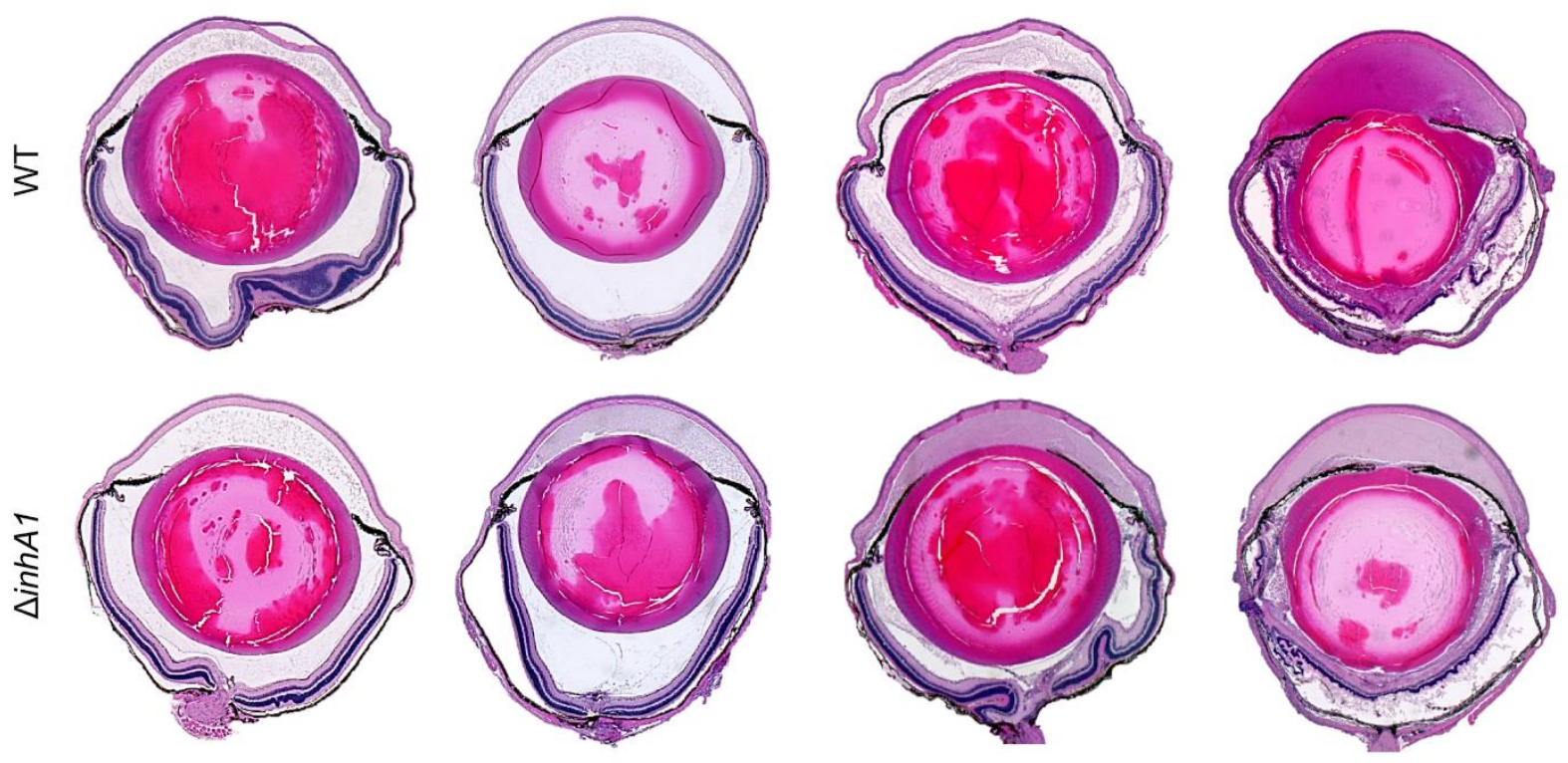

$6 \mathrm{hr}$

$8 \mathrm{hr}$

$10 \mathrm{hr}$

$12 \mathrm{hr}$ 
Figure 5

A

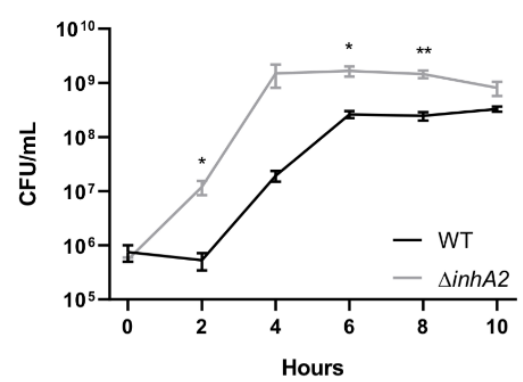

D

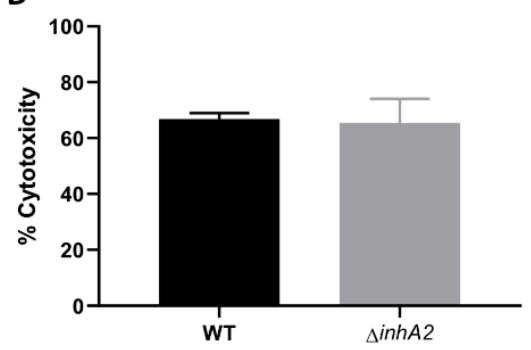

B

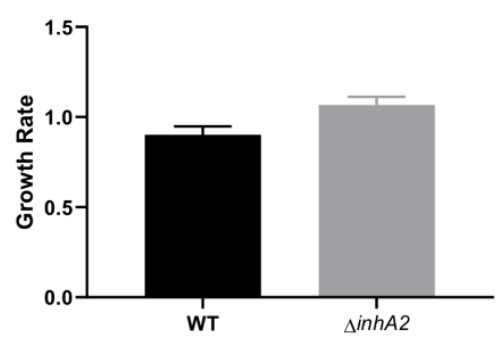

E

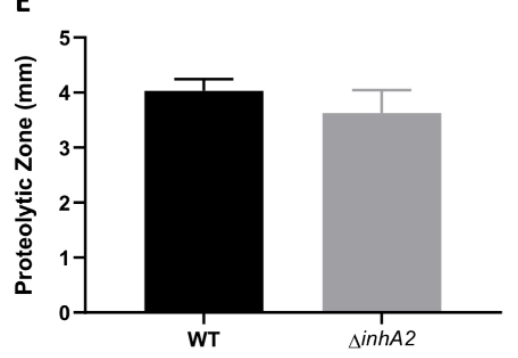

C

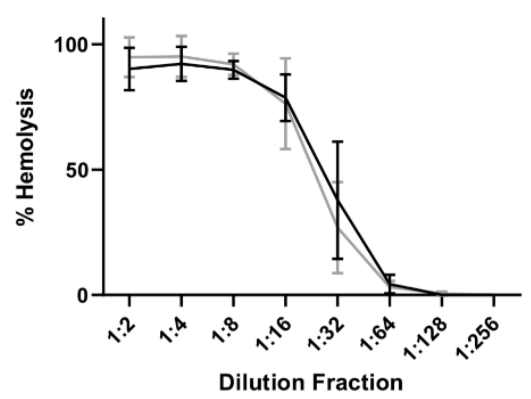


819 Figure 6

A

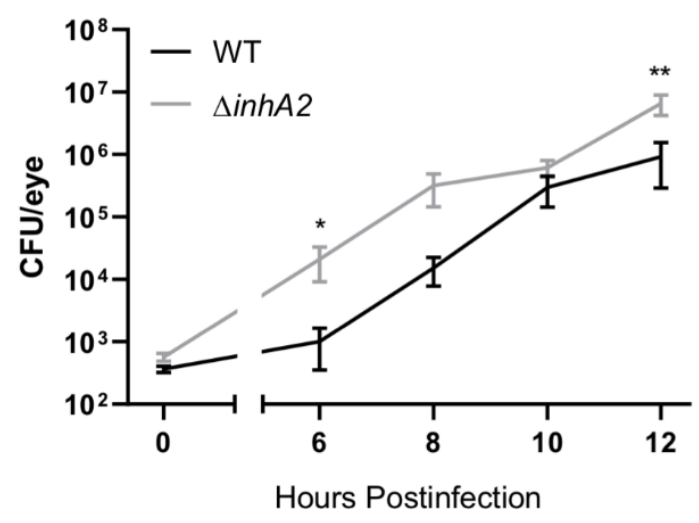

B

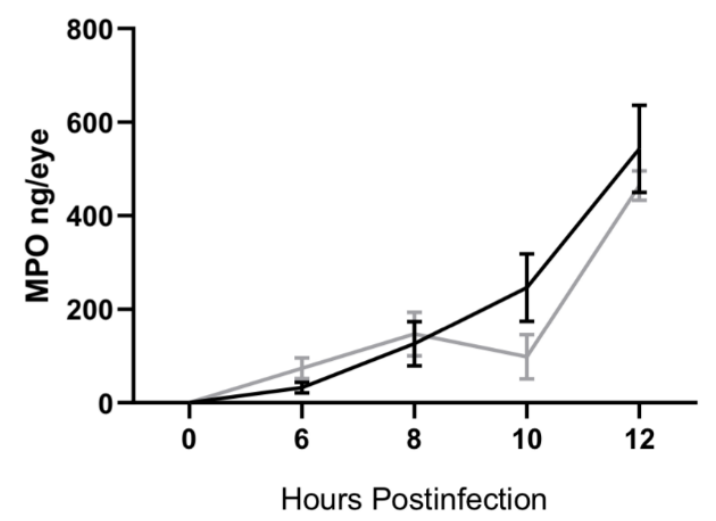


A

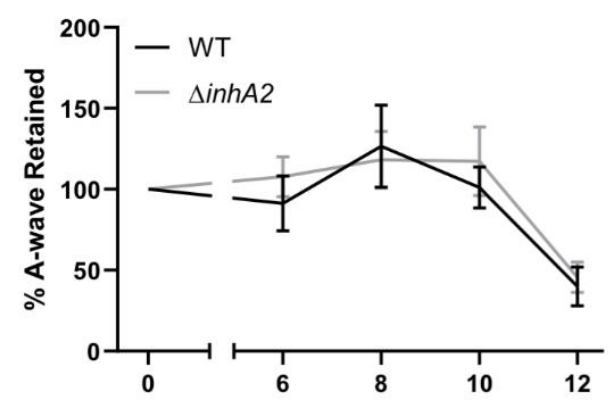

C

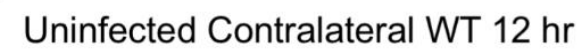

837

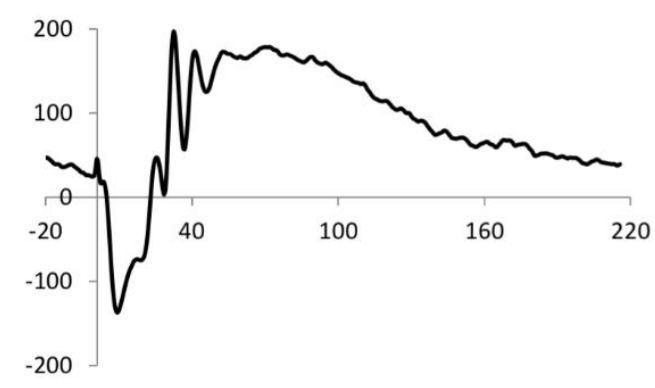

Uninfected Contralateral $\triangle i n h A 212 \mathrm{hr}$

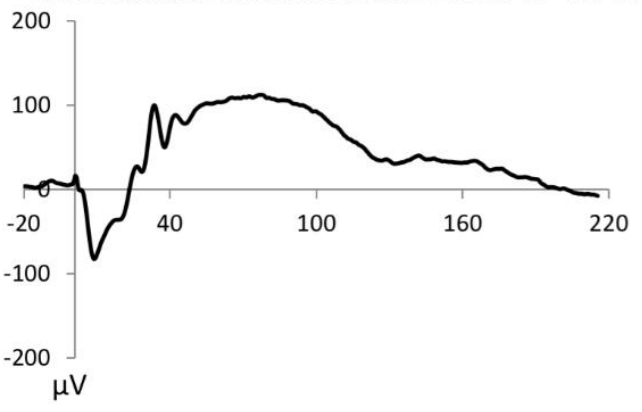

B

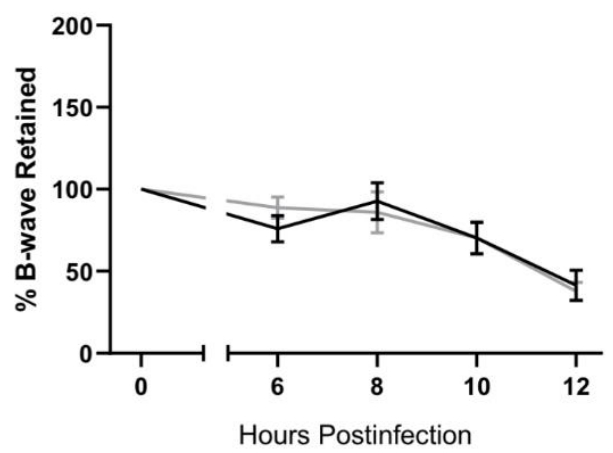

Infected WT $12 \mathrm{hr}$
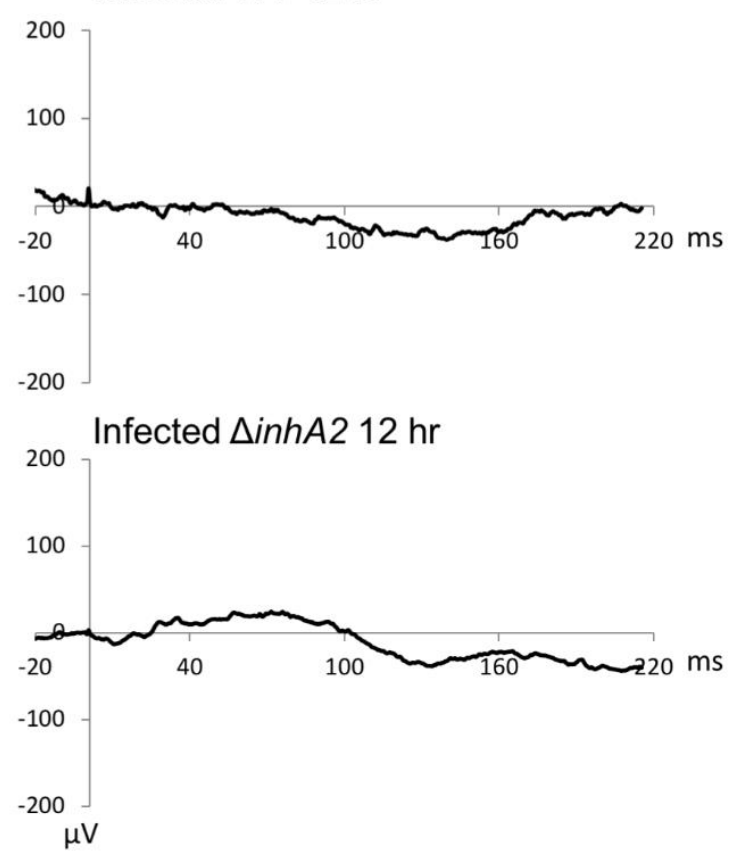

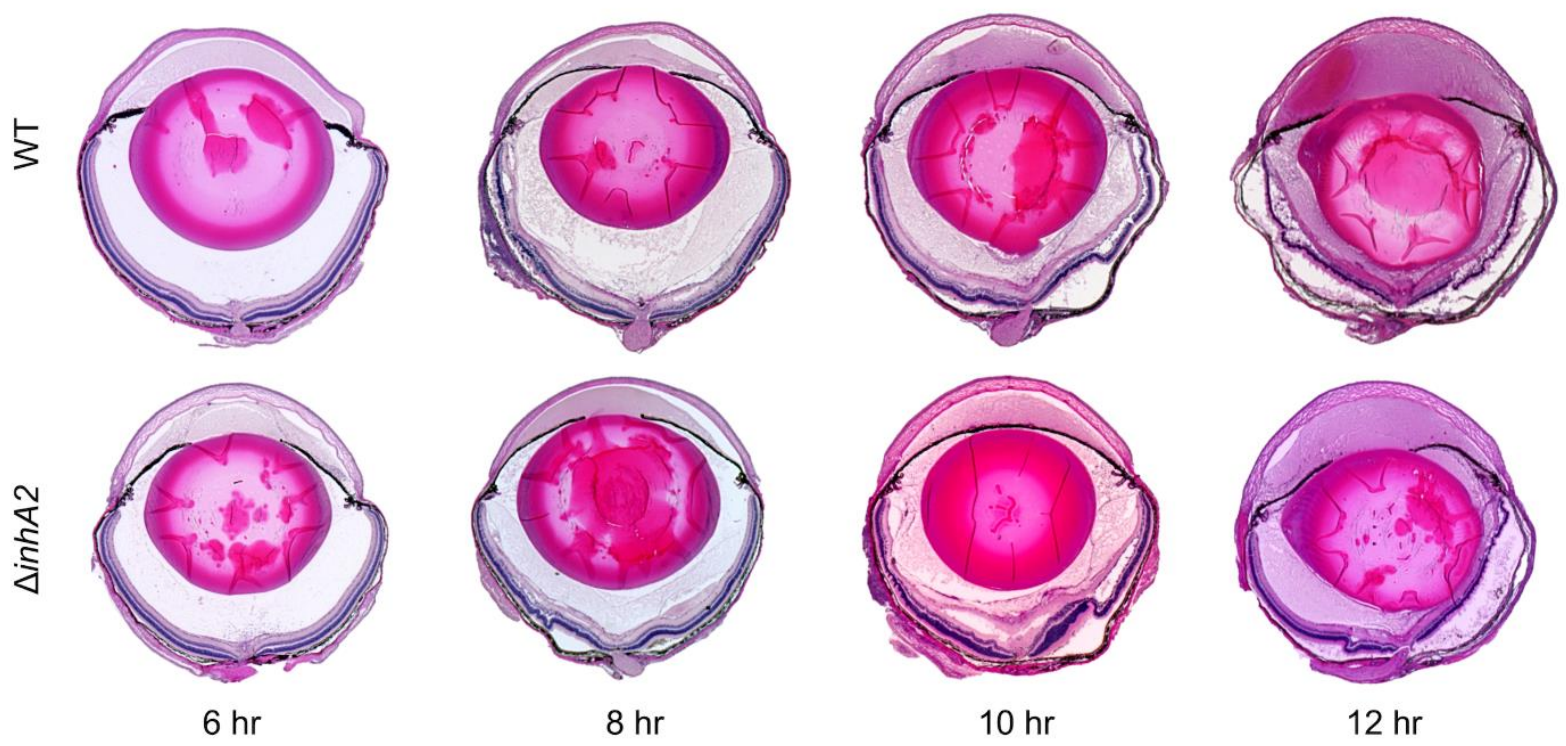

Hours Postinfection 

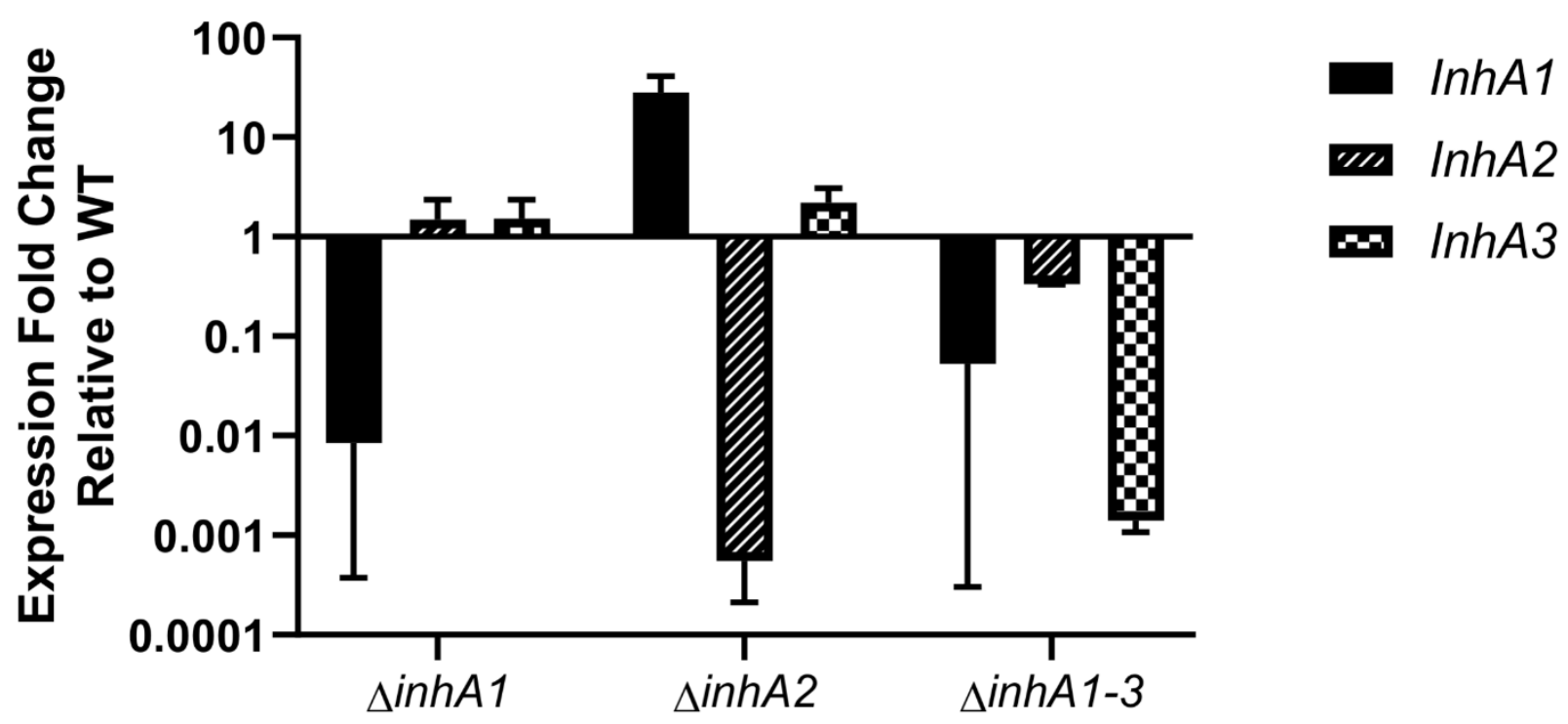
A

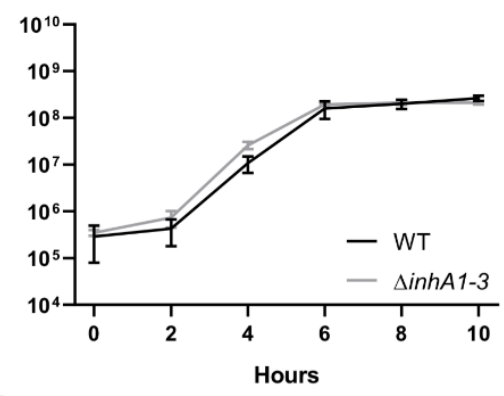

D

876

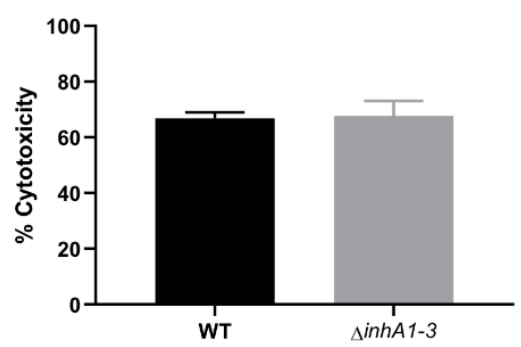

B

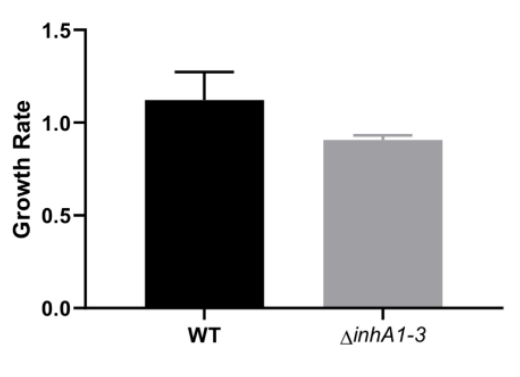

E

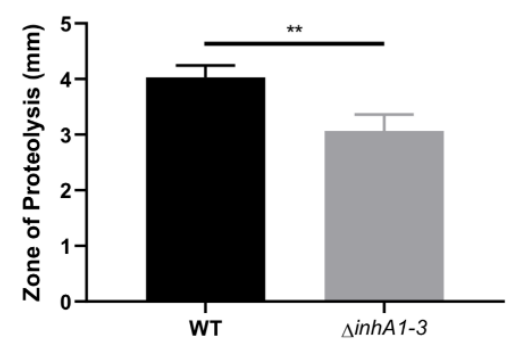

C

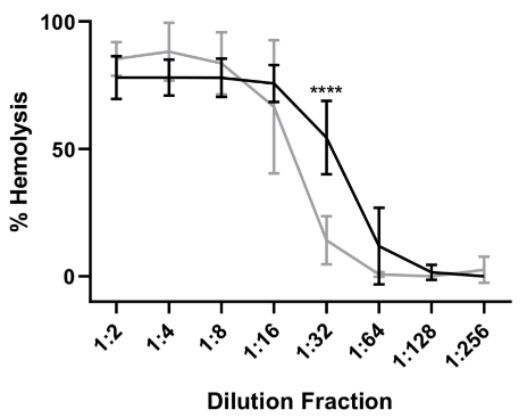

877 
A

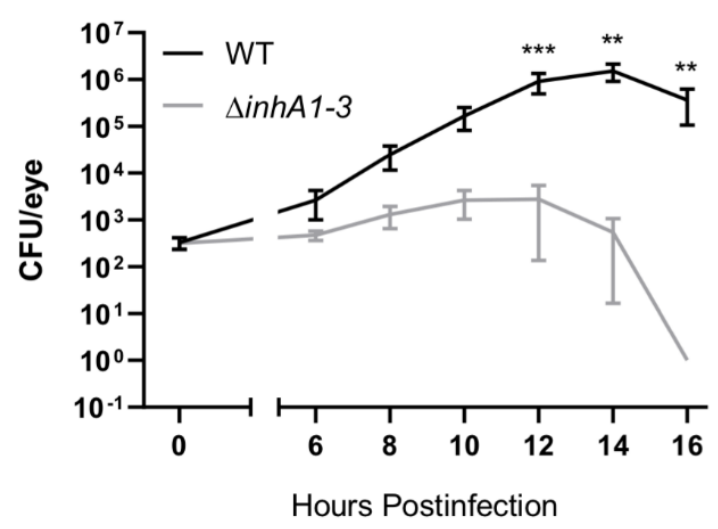

B

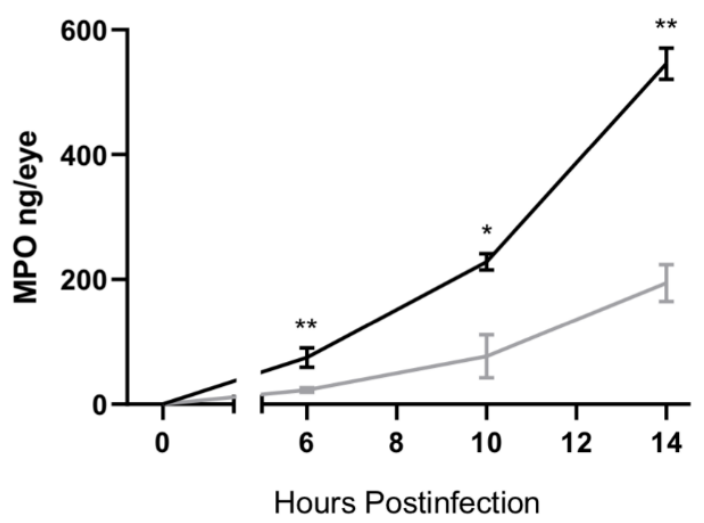


907 Figure 12

A

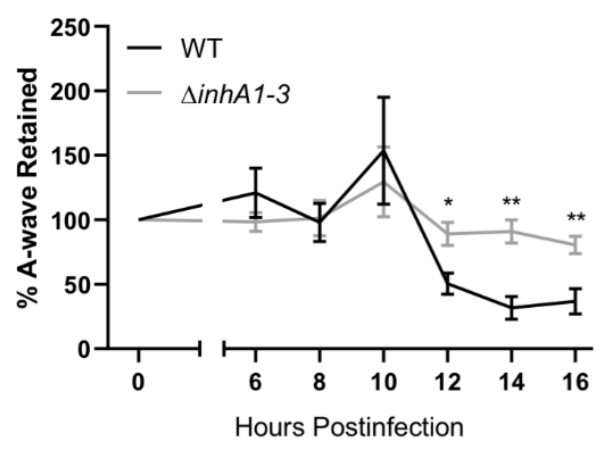

C

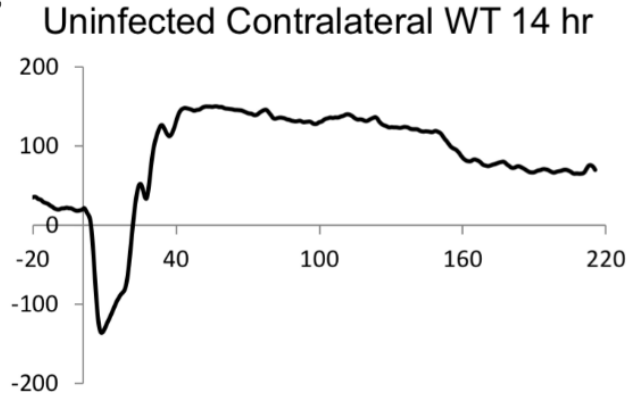

Uninfected Contralateral $\Delta i n h A 1-314 \mathrm{hr}$

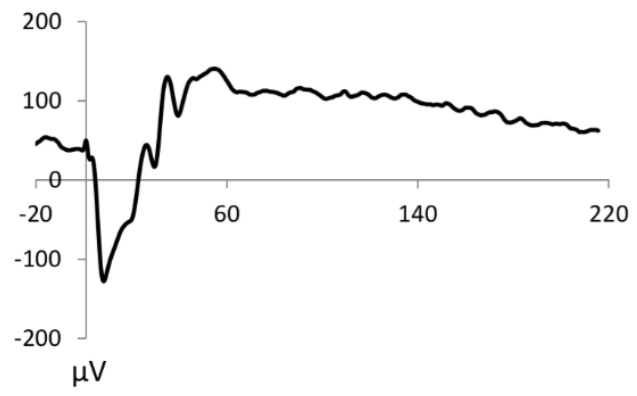

B
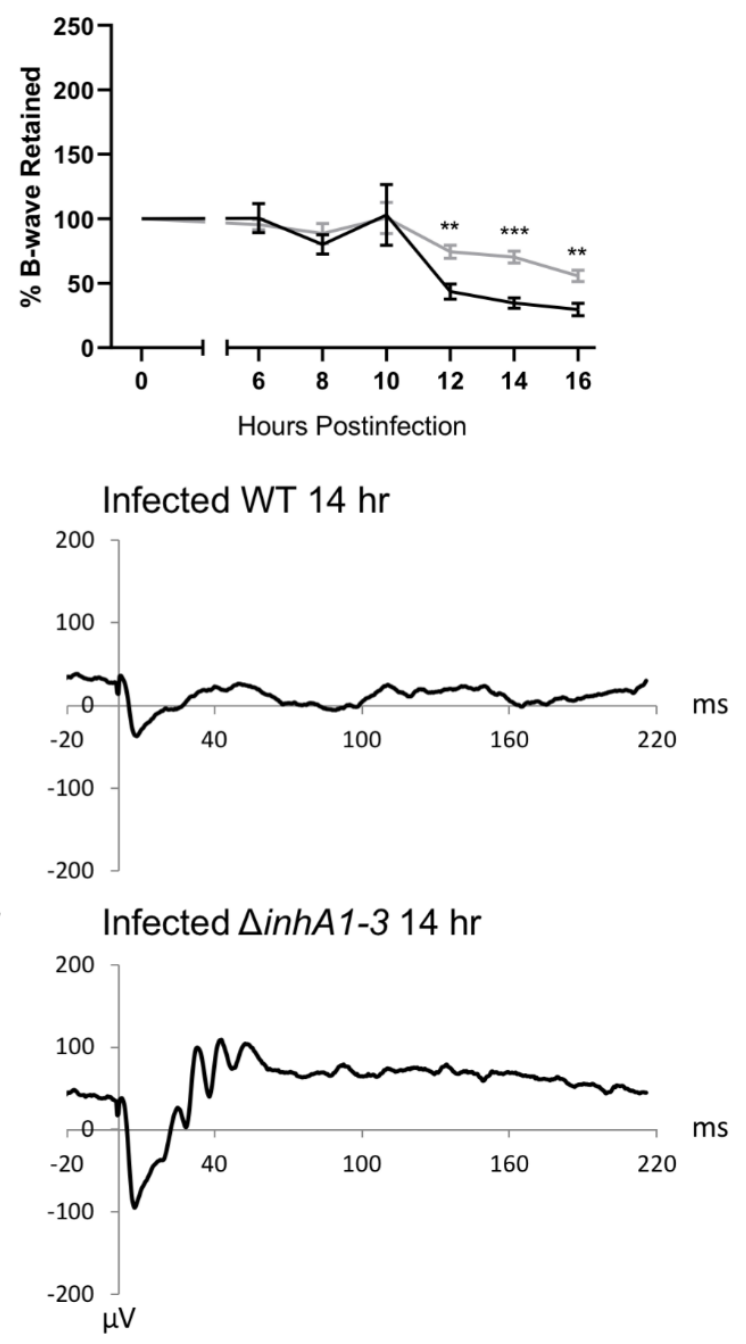

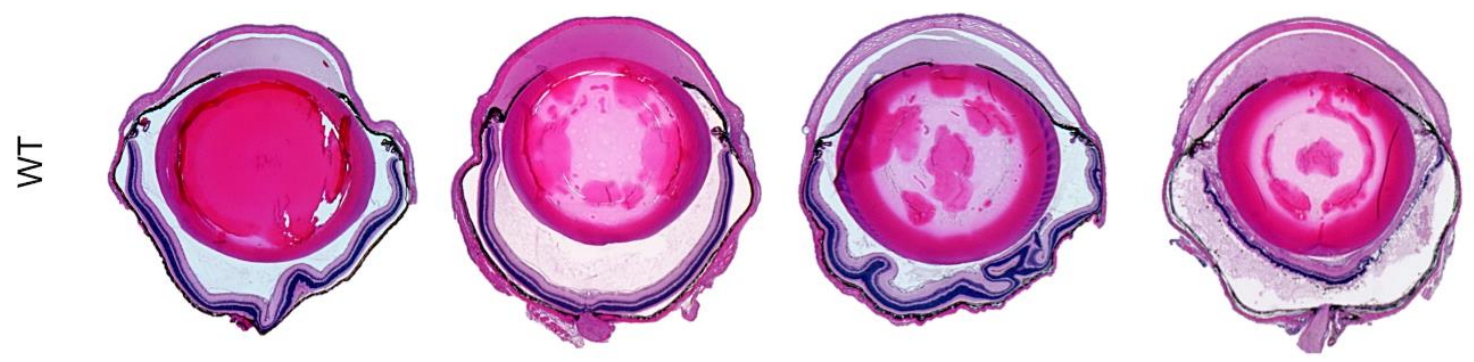

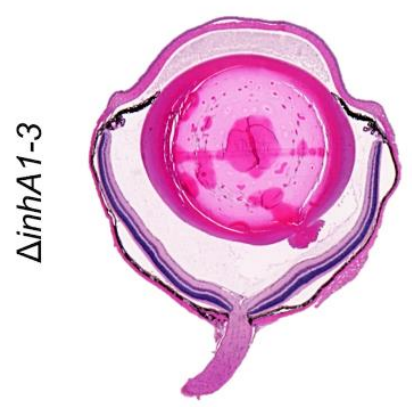

$6 \mathrm{hr}$

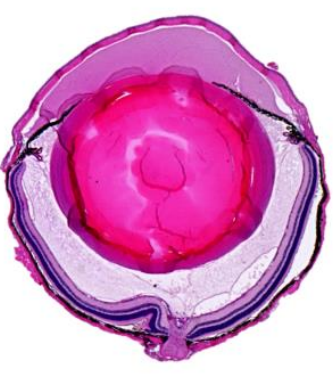

$8 \mathrm{hr}$

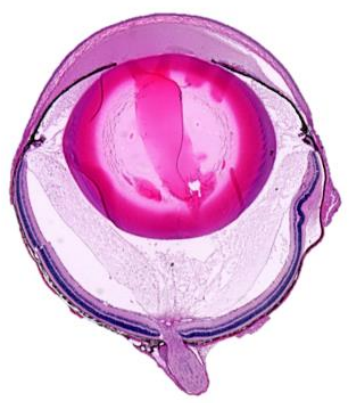

$10 \mathrm{hr}$

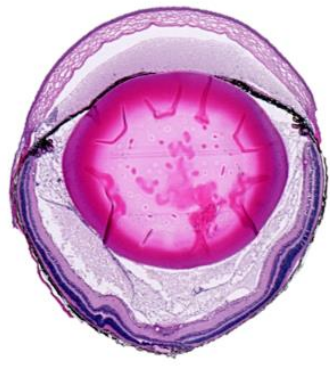

$12 \mathrm{hr}$ 


\section{Figure Legends}

931

Figure 1. Absence of InhA1 in Bacillus alters growth and proteolysis. (A) In vitro growth curve of WT B. thuringiensis and its isogenic InhA1-deficient mutant ( $\triangle i n h A 1)$ in BHI broth. CFU of $\triangle i n h A 1 B$. thuringiensis were increased compared to WT at 2,4 , and 6 hours $(P<0.05)$.

943 for $N=4$ samples.

Figure 2. Absence of InhA1 Affects Intraocular Bacterial Burden But Not Inflammation in

947 isogenic InhA1-deficient mutant $(\triangle i n h A 1)$. (A) At the indicated times postinfection, eyes were harvested and CFU quantified for bacterial intraocular growth. Data represents the mean $\pm \mathrm{SEM}$ of $\log _{10}$ CFU/eye of $N \geq 4$ eyes per time point for at least two separate experiments. ns: $P>0.05$ at 0 and 10 hours postinfection. $* P<0.05$ at 6,8 , and 12 hours postinfection. (B) Infected eyes were harvested and infiltration of PMN was assessed by quantifying MPO in whole eyes by 
953 points. Values represent the mean \pm SEM of MPO (ng/eye) of $N \geq 4$ per time point for at least 954 two separate experiments.

Figure 3. Retinal Function is Not Preserved in the Absence of InhA1. C57BL/6J mouse eyes were injected with 200 CFU WT or $\triangle i n h A 1 B$. thuringiensis and retinal function was assessed by ERG. (A) Retained A-wave function of WT-infected eyes was similar to eyes infected with $\triangle i n h A 2 B$. thuringiensis at 6,8 , and 10 hours postinfection $(P>0.05) .{ }^{*} P<0.05$ at 12 hours postinfection. (B) B-wave function was also similar in eyes infected with WT and $\triangle i n h A 1 B$. thuringiensis at 6, 8, 10, and 12 hours postinfection $(P>0.05)$. (C) Representative waveforms from eyes infected with WT or $\triangle i n h A 1 B$. thuringiensis at 12 hours postinfection. In these mice, one eye was infected and the contralateral eye served as the uninfected control. Values represent the mean \pm SEM of percentage amplitude retained per time point for at least two separate experiments. Data are representative of $N \geq 6$ eyes per time point. were infected with $200 \mathrm{CFU}$ of WT or $\triangle i n h A 1$ B. thuringiensis. Infected eyes were harvested at 6, 8, 10, and 12 hours postinfection and processed for H\&E staining. Magnification, $\times 10$.

Figure 5. Absence of InhA2 in Bacillus Alters Growth. (A) In vitro growth curve of WT $B$.

972 thuringiensis and its isogenic InhA2-deficient mutant $(\triangle i n h A 2)$ in BHI broth. CFU of $\triangle i n h A 2 B$.

973 thuringiensis were increased compared to WT at 2, 6, and 8 hours $(P<0.05)$. Values represent

974 the mean $\pm \mathrm{SEM}$ for $N=3$ samples per time point. (B) Filter sterilized supernatants of WT and

$975 \Delta i n h A 2 B$. thuringiensis were compared for their hemolytic activities at varying dilutions $(P>$ 
976

977

978

979

980

981

982

983

984

985

986

987

988

989

990

991

992

993

994

995

996

997

998

0.05). (C) Cytotoxicity of filter sterilized overnight supernatants from WT and $\triangle i n h A 2 B$.

thuringiensis in human retinal pigment epithelial cells. No significant difference was observed in the cytotoxicity of these strains $(P>0.05)$. Data represents the mean $\pm \mathrm{SEM}$ of percent of cytotoxicity for $N=3$ samples. (D) Proteolysis of WT and $\Delta i n h A 2 B$. thuringiensis were compared by measuring lytic zones around colonies on milk agar. Lytic zones of $\triangle i n h A 2 B$. thuringiensis were similar to $W T(P>0.05)$. Values represent the mean $\pm \mathrm{SEM}$ for $N=4$ samples.

\section{Figure 6. Absence of InhA2 Increases Bacterial Burden but not Inflammation in}

Endophthalmitis. C57BL/6J mouse eyes were injected with 200 CFU WT B. thuringiensis or its isogenic InhA2-deficient mutant $(\triangle i n h A 2)$. (A) At the indicated times postinfection, eyes were harvested and CFU quantified for bacterial intraocular growth. Data represents the mean $\pm \mathrm{SEM}$ of $\log _{10}$ CFU/eye of $N \geq 4$ eyes per time point for at least two separate experiments. ns: $P>0.05$ at 0,8 , and 10 hours postinfection. $* P<0.05$ at 6 hours postinfection, and ${ }^{*} * \mathrm{P}<0.005$ at 12 hours postinfection. (B) Infected eyes were harvested and infiltration of PMN was assessed by quantifying MPO in whole eyes by sandwich ELISA. MPO levels of $\triangle i n h A 2$-infected eyes were similar to WT strains at all time points. Values represent the mean \pm SEM of MPO (ng/eye) of $N \geq 4$ per time point for at least two separate experiments.

Figure 7. Absence of InhA2 Does Not Affect Retinal Function. C57BL/6J mouse eyes were injected with $200 \mathrm{CFU}$ WT or $\triangle i n h A 2$ B. thuringiensis and retinal function was assessed by ERG. (A) Retained A-wave function of WT-infected eyes was similar to eyes infected with $\triangle i n h A 2$ B. thuringiensis at 6, 8, 10, and 12 hours postinfection $(P>0.05)$. (B) B-wave function 
was also similar in eyes infected with WT and $\triangle i n h A 2 B$. thuringiensis at 6, 8, 10, and 12 hours

1000

1001

1002

1003

1004

1005

1006

1007

1008

1009

1010

1011

1012

1013

1014

1015

1016

1017

1018

1019

1020

1021

postinfection $(P>0.05)$. (C) Representative waveforms from eyes infected with WT or $\triangle i n h A 2$

B. thuringiensis at 12 hours postinfection. In these mice, one eye was infected and the

contralateral eye served as the uninfected control. Values represent the mean $\pm \mathrm{SEM}$ of

percentage amplitude retained per time point for at least two separate experiments. Data are representative of $N \geq 6$ eyes per time point.

Figure 8. Ocular Damage and Inflammation are Similar Between WT and $\Delta i n h A 2$ Strains in Endophthalmitis. C57BL/6J mouse eyes were infected with $200 \mathrm{CFU}$ of WT or $\triangle i n h A 2 B$. thuringiensis. Infected eyes were harvested at 6, 8, 10, and 12 hours postinfection and processed for H\&E staining. Magnification, $\times 10$.

\section{Figure 9. Compensation of InhA Expression in Single InhA Mutants. Quantitative RT-PCR}

of mutant strains detecting inhA1, inhA2, and inhA3 in overnight cultures grown in BHI. $16 \mathrm{~S}$

ribosomal RNA was used as a control. Values represent the mean $\pm \mathrm{SD}$ of expression fold change relative to the expression in WT. Data are representative of at least two separate experiments, and are representative of $\mathrm{N}=3$.

\section{Figure 10. Absence of InhA1, InhA2, and InhA3 in Bacillus Alters Proteolysis. (A) In vitro}

growth curve of WT B. thuringiensis and its isogenic InhA1-3-deficient mutant $(\triangle i n h A 1-3)$ in

BHI broth. CFU of $\triangle i n h A 1-3$ B. thuringiensis was similar to WT at all time points $(P<0.05)$.

Values represent the mean \pm SEM for $N=3$ samples per time point. (B) Filter sterilized

supernatants of WT and $\Delta i n h A 1-3$ B. thuringiensis were compared for their hemolytic activities 
1022 at varying dilutions $(P>0.05)$. (C) Cytotoxicity of filter sterilized overnight supernatants from

1023 WT and $\Delta i n h A 1-3$ B. thuringiensis in human retinal pigment epithelial cells. A significant

1024 difference was observed in the cytotoxicity of these strains at the 1:32 dilution fraction

$1025(P>0.05)$. Data represents the mean \pm SEM of percent of cytotoxicity for $N=3$ samples. (D)

1026 Proteolysis of WT and $\Delta i n h A 1-3$ B. thuringiensis were compared by measuring lytic zones

1027 around colonies on milk agar. Lytic zones of $\Delta i n h A 1-3$ B. thuringiensis were significantly less 1028 compared to WT $(P>0.05)$. Values represent the mean $\pm \mathrm{SEM}$ for $N=4$ samples.

\section{Figure 11. Absence of InhA1-3 Alters Intraocular Bacterial Burden and Inflammation in}

Endophthalmitis. C57BL/6J mouse eyes were injected with 200 CFU WT B. thuringiensis or its

1032

1033

1034

1035

1036

1037

1038

1039

1040

1041

1042

1043

1044

isogenic InhA1-3-deficient mutant ( $\Delta i n h A 1-3)$. (A) At the indicated times postinfection, eyes

were harvested and CFU quantified for bacterial intraocular growth. Data represents the mean \pm

SEM of $\log _{10}$ CFU/eye of $N \geq 4$ eyes per time point for at least two separate experiments. $\mathrm{P}>$

0.05 at 12,14 , and 16 hours postinfection. $* * \mathrm{P}<0.005$ at 14 and 16 hours postinfection, and

$* * * \mathrm{P}<0.0005$ at 12 hours postinfection. (B) Infected eyes were harvested and infiltration of

PMN was assessed by quantifying MPO in whole eyes by sandwich ELISA. MPO levels of

$\Delta$ inhA1-3-infected eyes were significantly less compared to WT strains at all time points. $* \mathrm{P}<$

0.05 at 10 hours postinfection, and $* * \mathrm{P}<0.005$ at 6 and 14 hours postinfection. Values represent

the mean \pm SEM of MPO (ng/eye) of $\mathrm{N} \geq 4$ per time point for at least two separate experiments.

\section{Figure 12. Retained Retinal Function in eyes infected with Bacillus lacking InhA1-3.}

C57BL/6J mouse eyes were injected with $200 \mathrm{CFU}$ WT or $\Delta i n h A 1-3$ B. thuringiensis and retinal function was assessed by ERG. (A) Retained A-wave function of WT-infected eyes was 
1045 significantly higher to eyes infected with $\Delta$ inhAl-3 B. thuringiensis at 12, 14, and 16 hours

1046 postinfection. (B) B-wave function was also higher in eyes infected with $\triangle i n h A 2 B$.

1047 thuringiensis at 12,14 , and 16 hours postinfection. $* \mathrm{P}<0.05, * * \mathrm{P}<0.005$, and $* * * \mathrm{P}<0.0005$.

1048 (C) Representative waveforms from eyes infected with WT or $\Delta i n h A 1-3$ B. thuringiensis at 12

1049 hours postinfection. In these mice, one eye was infected and the contralateral eye served as the

1050 uninfected control. Values represent the mean \pm SEM of percentage amplitude retained per time

1051 point for at least two separate experiments. Data are representative of $\mathrm{N} \geq 6$ eyes per time point.

1052

1053 Figure 13. Ocular architecture is preserved in the absence of $\operatorname{Inh} A 1-3$.

$1054 \mathrm{C} 57 \mathrm{BL} / 6 \mathrm{~J}$ mouse eyes were infected with $200 \mathrm{CFU}$ of WT or $\Delta$ inhA1-3 B. thuringiensis.

1055 Infected eyes were harvested at 6, 8, 10, and 12 hours postinfection and processed for $\mathrm{H} \& \mathrm{E}$

1056 staining. Magnification, $\times 10$. 